University of Nebraska - Lincoln

DigitalCommons@University of Nebraska - Lincoln

US Department of Energy Publications

U.S. Department of Energy

2003

\title{
Desorption kinetics of radiocesium from subsurface sediments at Hanford Site, USA
}

Chongxuan Liu

Pacific Northwest National Laboratory, chongxuan.liu@pnl.gov

John M. Zachara

Pacific Northwest National Laboratory, john.zachara@pnl.gov

Steven Smith

Pacific Northwest National Laboratory, steven.smith@pnl.gov

James Mckinley

Pacific Northwest National Laboratory, james.mckinley@pnl.gov

Calvin Ainsworth

Pacific Northwest National Laboratory

Follow this and additional works at: https://digitalcommons.unl.edu/usdoepub

Part of the Bioresource and Agricultural Engineering Commons

Liu, Chongxuan; Zachara, John M.; Smith, Steven; Mckinley, James; and Ainsworth, Calvin, "Desorption kinetics of radiocesium from subsurface sediments at Hanford Site, USA" (2003). US Department of Energy Publications. 252.

https://digitalcommons.unl.edu/usdoepub/252

This Article is brought to you for free and open access by the U.S. Department of Energy at DigitalCommons@University of Nebraska - Lincoln. It has been accepted for inclusion in US Department of Energy Publications by an authorized administrator of DigitalCommons@University of Nebraska - Lincoln. 


\title{
doi:10.1016/S0016-7037(00)00267-9
}

\section{Desorption kinetics of radiocesium from subsurface sediments at Hanford Site, USA}

\author{
Chongxuan Liu,* John M. Zachara, Steve C. Smith, James P. McKinley, and Calvin C. Ainsworth \\ Pacific Northwest National Laboratory, P.O. Box 999, MSIN K8-96, Richland, WA 99352, USA
}

(Received September 25, 2002; accepted in revised form April 16, 2003)

\begin{abstract}
The desorption of ${ }^{137} \mathrm{Cs}^{+}$was investigated on sediments from the United States Hanford site. Pristine sediments and ones that were contaminated by the accidental release of alkaline ${ }^{137} \mathrm{Cs}^{+}$-containing high level nuclear wastes (HLW, $2 \times 10^{6}$ to $6 \times 10^{7} \mathrm{pCi}^{137} \mathrm{Cs}^{+} / \mathrm{g}$ ) were studied. The desorption of ${ }^{137} \mathrm{Cs}^{+}$ was measured in $\mathrm{Na}^{+}, \mathrm{K}^{+}, \mathrm{Rb}^{+}$, and $\mathrm{NH}_{4}{ }^{+}$electrolytes of variable concentration and $\mathrm{pH}$, and in presence of a strong $\mathrm{Cs}^{+}$-specific sorbent (self-assembled monolayer on a mesoporous support, SAMMS). ${ }^{137} \mathrm{Cs}^{+}$ desorption from the HLW-contaminated Hanford sediments exhibited two distinct phases: an initial instantaneous release followed by a slow kinetic process. The extent of ${ }^{137} \mathrm{Cs}^{+}$desorption increased with increasing electrolyte concentration and followed a trend of $\mathrm{Rb}^{+} \geq \mathrm{K}^{+}>\mathrm{Na}^{+}$at circumneutral $\mathrm{pH}$. This trend followed the respective selectivities of these cations for the sediment. The extent and rate of ${ }^{137} \mathrm{Cs}^{+}$desorption was influenced by surface armoring, intraparticle diffusion, and the collapse of edge-interlayer sites in solutions containing $\mathrm{K}^{+}, \mathrm{Rb}^{+}$, or $\mathrm{NH}_{4}{ }^{+}$. Scanning electron microscopic analysis revealed HLW-induced precipitation of secondary aluminosilicates on the edges and basal planes of micaceous minerals that were primary $\mathrm{Cs}^{+}$ sorbents. The removal of these precipitates by acidified ammonium oxalate extraction significantly increased the long-term desorption rate and extent. X-ray microprobe analyses of $\mathrm{Cs}^{+}$-sorbed micas showed that the ${ }^{137} \mathrm{Cs}^{+}$distributed not only on mica edges, but also within internal channels parallel to the basal plane, implying intraparticle diffusive migration of ${ }^{137} \mathrm{Cs}^{+}$. Controlled desorption experiments using $\mathrm{Cs}^{+}$-spiked pristine sediment indicated that the ${ }^{137} \mathrm{Cs}^{+}$diffusion rate was fast in $\mathrm{Na}^{+}$-electrolyte, but much slower in the presence of $\mathrm{K}^{+}$or $\mathrm{Rb}^{+}$, suggesting an effect of edge-interlayer collapse. An intraparticle diffusion model coupled with a two-site cation exchange model was used to interpret the experimental results. Model simulations suggested that about $40 \%$ of total sorbed ${ }^{137} \mathrm{Cs}^{+}$was exchangeable, including equilibrium and kinetic desorbable pools. At $\mathrm{pH} 3$, this ratio increased to $60-80 \%$. The remainder of the sorbed ${ }^{137} \mathrm{Cs}^{+}$was fixed or desorbed at much slower rate than our experiments could detect. Copyright (C) 2003 Elsevier Ltd
\end{abstract}

\section{INTRODUCTION}

Cesium-137 is produced in high yield by fission of ${ }^{238} \mathrm{U}$, and is a common contaminant resulting from nuclear weapons testing and nuclear fuels reprocessing. The aqueous concentration and subsurface migration of ${ }^{137} \mathrm{Cs}^{+}$is controlled by its strong sorption to and desorption from soils and sediments. Cesium sorption and desorption is influenced by sorbent properties, such as mineralogy and cation exchange capacity (CEC), competing cations, such as $\mathrm{Na}^{+}$and $\mathrm{K}^{+}$, and age of the sorption complex. An understanding of the $\mathrm{Cs}^{+}$sorption/desorption process is important for evaluating the environmental risks associated with the radiocesium migration and the feasibility of remediation strategies.

$\mathrm{Cs}^{+}$sorption occurs primarily by ion exchange to the phyllosilicate fraction of soil or sediment. Experimentally measured $\mathrm{Cs}^{+}$-exchange isotherms often imply the presence of two or more sites with distinctive exchange energies (Sawhney, 1972; Brouwer et al., 1983; Cornell, 1993; Zachara et al., 2002). The high-energy site is believed to be associated with frayed-edge regions of weathered $1.0 \mathrm{~nm}$ micaceous minerals, and the low energy sites with the basal planes of expansible phyllosilicates including smectite and vermiculite. The presence of multiple sorption sites has been generally confirmed by NMR studies of $\mathrm{Cs}^{+}$-exchanged clay minerals (Weiss et al., 1990a,b; Kim et al., 1996). The short-term sorption/exchange of $\mathrm{Cs}^{+}$often exhibits

* Author to whom correspondence should be addressed (chongxuan. liu@pnl.gov). reversible behavior (Brouwer et al., 1983; Zachara et al., 2002), and has been described by multi-site, equilibrium exchange models (Brouwer et al., 1983; Cremers et al., 1988; Poinssot et al., 1999; Steefel et al., 2002; Zachara et al., 2002).

The sorption and desorption of $\mathrm{Cs}^{+}$can exhibit kinetic behavior over longer contact periods (Evans et al., 1983; Di Toro et al., 1986; De Preter, 1990; Comans et al., 1991). Slow diffusion of $\mathrm{Cs}^{+}$within edge-interlayer regions of micaceous minerals, accentuated by layer collapse around the poorly hydrated $\mathrm{Cs}^{+}$ion, is believed to cause this kinetic phenomenon (Sawhney, 1967, 1969, 1972; Eberl, 1980). Such diffusion may take days, months, years, or even decades for sorption/desorption to reach the equilibrium state depending on the structure of the mineral sorbents and the aqueous composition (Evans et al., 1983; Di Toro et al., 1986; De Preter, 1990; Comans et al., 1991).

Edge and/or interlayer collapse on phyllosilicate sorbents slows $\mathrm{Cs}^{+}$desorption leading to exchange irreversibility or fixation (e.g., Sawhney, 1972; Evans et al., 1983; De Preter, 1990; Comans et al., 1991). Debate exists whether "fixed" Cs ${ }^{+}$ is, or is not, exchangeable at slow rate (Comans et al., 1991; Cornell, 1993). The sorption of other exchangeable cations with low hydration energy, such as $\mathrm{K}^{+}, \mathrm{Rb}^{+}$, and $\mathrm{NH}_{4}{ }^{+}$, may also collapse the edge-interlayer region, decreasing $\mathrm{Cs}^{+}$adsorption and desorption rate (Sawhney, 1967, 1972; Le Roux et al., 1970). In contrast, strongly hydrated cations (e.g., $\mathrm{Na}^{+}$and $\mathrm{Ca}^{2+}$ ) may expand the edge-interlayer region-inducing an opposite effect. 
The phenomenological aspects of $\mathrm{Cs}^{+}$desorption are understood primarily from investigations of single-phase 2:1 layer silicates. Comparable studies of $\mathrm{Cs}^{+}$-contaminated soil and sediment are relatively rare. Long-term exposure allows $\mathrm{Cs}^{+}$ diffusion into edge-interlayer regions of micaceous sorbents. Limited study suggests that desorption rate and extent decreases with contact time (Evans et al., 1983; Smith and Comans, 1996), but controlling features and parameters are not understood. Understanding $\mathrm{Cs}^{+}$desorption from natural sediments subjected to long-term contamination is key to predicting future $\mathrm{Cs}^{+}$migration.

In this communication, we investigate factors controlling $\mathrm{Cs}^{+}$desorption from micaceous sediments that were contaminated with a ${ }^{137} \mathrm{Cs}^{+}$-enriched high-level nuclear waste (HLW) stream over $30 \mathrm{yr}$ ago. The HLW was geochemically reactive (high $\left[\mathrm{Na}^{+}\right]$and $\left[\mathrm{OH}^{-}\right]$, temperature $>70^{\circ} \mathrm{C}$ ), inducing both dissolution and precipitation reactions upon sediment contact that moderated with distance from the waste source. A series of sediment samples collected with increasing distance from the waste source and varying in sorbed ${ }^{137} \mathrm{Cs}^{+}$concentration were contacted with different electrolytes $\left(\mathrm{Na}^{+}, \mathrm{K}^{+}, \mathrm{NH}_{4}{ }^{+}\right.$, and $\mathrm{Rb}^{+}$) and $\mathrm{a} \mathrm{Cs}^{+}$-specific sorbent to quantify desorption rate and extent. Scanning electron and X-ray microscopy was applied to identify the degree of mineral alteration and $\mathrm{Cs}^{+}$-sorption location. Equilibrium and kinetic modeling was used to quantify ion exchange mass action effects, and to derive mass transfer parameters consistent with data trends. Secondary mineral precipitation, intraparticle diffusion, and edge collapse all appear to influence the release of ${ }^{137} \mathrm{Cs}^{+}$from the contaminated sediments and insights are provided on their relative importance.

\section{EXPERIMENTAL PROCEDURES}

\subsection{Sediment Collection and Analysis}

${ }^{137} \mathrm{Cs}^{+}$-contaminated sediments were obtained from two boreholes (SX-108, 41-09-39) in the Hanford S-SX tank farm and included SX-108 samples 3A (20.6 m below ground surface [bgs]) and 7A (25.8 m bgs), and 41-09-39 samples 7ABC $(25.3 \mathrm{~m} \mathrm{bgs})$ and $9 \mathrm{ABC}(22.8 \mathrm{~m} \mathrm{bgs})$. The collection and analyses of the sediments was described elsewhere (Serne et al., 2001a,b). Subsamples of the field moist materials were air-dried to a constant weight and sieved to pass a $2 \mathrm{~mm}$ mesh. Gravels $>2 \mathrm{~mm}$ were removed from the air-dried materials during the sieving process. The sieved materials were mixed as well as possible given their high radioactivity to obtain a homogenized sample.

Pristine sediments from comparable depth intervals were obtained from four RCRA monitoring wells surrounding the S-SX tank farm (Zachara et al., 2002) for use in controlled experiments of $\mathrm{Cs}^{+}$ion exchange and desorption. The pristine materials were treated in the same manner as the contaminated materials described above. The homogenized pristine sediments were termed the "Above B" composite. Both the pristine and contaminated sediments were obtained from the upper Hanford formation, which is a Pleistocene-age, catastrophic flood deposit. The mineralogical compositions of the pristine and contaminated sediments were the same except that the contaminated sediments were altered by HLW-sediment reaction.

The contaminated sediment contained a high level of residual salt $\left(\mathrm{NaNO}_{3}\right)$ from the HLW. Before drying, the moisture content of the sediment ranged between $2.8-6.2 \%$, and the pore-water concentration of $\mathrm{NaNO}_{3}$ associated with this moisture context ranged between 5 and $15 \mathrm{~mol} / \mathrm{L}$ (Liu et al., 2003). These pore-water concentrations were estimated by 1:1 deionized water extraction of the sediment (Serne et al., 2001a,b).

\subsection{Mass Action Effects on ${ }^{137} \mathrm{Cs}^{+}$Desorption}

Air-dried, sieved contaminated sediment ( $2 \mathrm{~g}$ ) was weighed into a $30 \mathrm{~mL}$ Oakridge polycarbonate centrifuge tube containing $4 \mathrm{~mL}$ of either $0.05,0.5$ or $5 \mathrm{~mol} / \mathrm{L} \mathrm{NaNO}_{3}$, or $0.05,0.5$ or $3.4 \mathrm{~mol} / \mathrm{L} \mathrm{KNO}_{3}$ or $\mathrm{RbNO}_{3}$. After equilibration for $6 \mathrm{~d}$ at $25^{\circ} \mathrm{C}$ under continuous mixing, the suspensions were centrifuged at $5000 \mathrm{rcf}$ (relative centrifugal force) for $30 \mathrm{~min}$ and supernatant $(0.5 \mathrm{~mL})$ was transferred to a preweighed gamma count vial and reweighed. The ${ }^{137} \mathrm{Cs}^{+}$activity of the sample was counted for 30 min using a Wallac gamma counter, model 1480 with an $76 \mathrm{~mm} \mathrm{NaI}$ crystal detector. The count window was set at 560 to $710 \mathrm{keV}$ yielding a count efficiency of 0.207 .

\subsection{Cation Exchange Capacity (CEC)}

Following the measurement of ${ }^{137} \mathrm{Cs}^{+}{ }_{\text {(aq) }}$ in the $6 \mathrm{~d}$ equilibration with $0.05,0.5$, or $5 \mathrm{~mol} / \mathrm{L} \mathrm{NaNO}_{3}$, the supernate was removed and replaced with $12 \mathrm{~mL}$ of $5 \mathrm{~mol} / \mathrm{L} \mathrm{NaNO}_{3}$. The sediment was washed four times with $5 \mathrm{~mol} / \mathrm{L} \mathrm{Na}^{+}$. The $\mathrm{Na}^{+}$-treated sediments were then washed with $12 \mathrm{~mL}$ of deionized water for $2 \mathrm{~d}$, and with $12 \mathrm{~mL}$ of $0.05 \mathrm{~mol} / \mathrm{L} \mathrm{Na}^{+}$for $2 \mathrm{~d}$. After the last wash, $4 \mathrm{~mL}$ of sediment suspension in $0.05 \mathrm{~mol} / \mathrm{L}$ $\mathrm{Na}^{+}$was mixed with $16 \mathrm{~mL}$ of ${ }^{22} \mathrm{Na}^{+}$in water (approximately $20,000 \mathrm{dpm} / \mathrm{mL}$ ). After $16 \mathrm{~h}$ of equilibration, the suspensions were centrifuged ( $5000 \mathrm{rcf}$ for $30 \mathrm{~min}$ ) and the ${ }^{22} \mathrm{Na}$ activity was determined in the supernatants. The $\mathrm{Na}^{+}$-cation exchange capacity was calculated from the initial and final ${ }^{22} \mathrm{Na}^{+}$counts in solution, and the aqueous $\mathrm{Na}^{+}$concentration. Aqueous $\mathrm{Na}^{+}$ in $0.2 \mu \mathrm{m}$ filtrate was determined by inductively coupled plasma-optical emission spectroscopy (ICP-OES).

The $\mathrm{Cs}^{+}$-cation exchange capacity was similarly determined. The sediments in the suspensions with $0.05,0.5$, or $5 \mathrm{~mol} / \mathrm{L}$ $\mathrm{NaNO}_{3}$ were repeatedly washed with $1 \mathrm{~mol} / \mathrm{L} \mathrm{CsNO}_{3}$, followed by two washes with deionized water, and two washes with 0.05 $\mathrm{mol} / \mathrm{L} \mathrm{CsNO}_{3}$. The $4 \mathrm{~mL}$ of sediment suspension at $0.05 \mathrm{~mol} / \mathrm{L}$ $\mathrm{CsNO}_{3}$ was mixed with $16 \mathrm{~mL}$ of ${ }^{134} \mathrm{Cs}^{+}$. After equilibration and centrifugation, the supernatants of the suspensions were filtered $(0.2 \mu \mathrm{m})$ for ICP-OES measurement of aqueous $\mathrm{Cs}^{+}$ and measurement of ${ }^{134} \mathrm{Cs}^{+}$activity.

\section{4. ${ }^{137} \mathrm{Cs}^{+}$Desorption Kinetics}

Two replicates of air-dried contaminated sediment $(0.5 \mathrm{~g})$ were weighed into $30 \mathrm{~mL}$ Oakridge polycarbonate centrifuge tubes and mixed with $5 \mathrm{~mL}$ of $0.5 \mathrm{~mol} / \mathrm{L} \mathrm{KNO}_{3}, \mathrm{RbNO}_{3}$, or $\mathrm{NH}_{4} \mathrm{NO}_{3}$. The suspensions were equilibrated with continual gentle mixing. At selected times, the suspensions were centrifuged (5000 $\mathrm{rcf}$ for $10 \mathrm{~min}$ ) and $0.5 \mathrm{~mL}$ of supernatant was transferred to a preweighed gamma count vial and reweighed. 
The aqueous ${ }^{137} \mathrm{Cs}^{+}$activity was measured as previously described. Following the determination of ${ }^{137} \mathrm{Cs}^{+}$activity, the subsample was returned to the suspension to maintain a constant solid to solution ratio. The final sampling time at 0.5 $\mathrm{mol} / \mathrm{L}$ electrolyte was $47 \mathrm{~d}$ in $\mathrm{KNO}_{3}$ and $\mathrm{RbNO}_{3}$, and $56 \mathrm{~d}$ in $\mathrm{NH}_{4} \mathrm{NO}_{3}$.

Following the $47 \mathrm{~d}$ of equilibration with $0.5 \mathrm{~mol} / \mathrm{L}$ of $\mathrm{K}^{+}$or $\mathrm{Rb}^{+}$electrolyte, the electrolyte concentration was increased to $2 \mathrm{~mol} / \mathrm{L}$ to evaluate the mass action effect on desorption kinetics. This was accomplished by transferring approximately $4 \mathrm{~mL}$ of each supernatant to a plastic tube containing a preweighed mass of dry $\mathrm{KNO}_{3}$ or $\mathrm{RbNO}_{3}$ necessary to raise the electrolyte concentration to the desired level without changing the solid to solution ratio. The added salt was dissolved within $2 \mathrm{~h}$ and the solutions were transferred back to their original containers for equilibration. At selected times, the suspension solution was sampled for aqueous ${ }^{137} \mathrm{Cs}^{+}$as previously described and returned to the suspension. Following the $65 \mathrm{~d}$ of equilibration the supernatants were filtered $(0.2 \mu \mathrm{m})$ for ICP-OES analysis of $\mathrm{K}^{+}$or $\mathrm{Rb}^{+}$concentrations.

\section{5. ${ }^{137} \mathrm{Cs}^{+}$Desorption Kinetics in Acidified Ammonium Oxalate (pH 3)}

The contaminated sediments were contacted with ammonium oxalate at $\mathrm{pH} 3$ to determine if poorly crystalline precipitates of $\mathrm{Fe}$ (III) and $\mathrm{Al}$ (III) resulting from waste-sediment reaction affected ${ }^{137} \mathrm{Cs}^{+}$desorption rate and extent. Replicate suspensions of each contaminated sediment $(0.5 \mathrm{~g})$ were prepared in $0.25 \mathrm{~mol} / \mathrm{L}\left(\mathrm{NH}_{4}\right)_{2}$-oxalate at $\mathrm{pH} 3(5 \mathrm{~mL})$ and sampled at select time points up to $134 \mathrm{~d}$. Phase separation was performed by centrifugation ( $5000 \mathrm{rcf}$ for $30 \mathrm{~min}$ ) and filtration $(0.2 \mu \mathrm{m})$. The first $1 \mathrm{~mL}$ of filtrate was discarded and the remaining collected in a plastic tube. Aqueous ${ }^{137} \mathrm{Cs}^{+}$was determined as previously described. Other elements in the filtrate ( $\mathrm{Fe}, \mathrm{Al}, \mathrm{Ba}, \mathrm{Ca}, \mathrm{Cr}, \mathrm{K}, \mathrm{Mg}, \mathrm{Na}$, and $\mathrm{Si}$ ) were analyzed using ICP-OES. Suspension $\mathrm{pH}$ was measured using a Microelectrodes combination $\mathrm{pH}$ electrode.

\section{6. ${ }^{137} \mathrm{Cs}^{+}$Desorption Induced by a Competitive Sorbent}

A Cs-specific sorbent, self-assembled monolayer on mesoporous support (SAMMS) (Lin et al., 2001), was used to expedite ${ }^{137} \mathrm{Cs}^{+}$desorption. The SAMMS contains an immobilized ferrocyanide complexant group for $\mathrm{Cs}^{+}$on a mesoporous, high surface area silica support. It has a property of high sorption capacity $(1.35 \mathrm{mmol} / \mathrm{g})$ and fast sorption kinetics (Lin et al., 2001). Approximately one gram of SX-108 7A sediment was transferred to cellulose dialysis membrane tubing (SpectraPor 7, $1000 \mathrm{MWCO}$ ) containing $5 \mathrm{~mL}$ of either 1 or $0.01 \mathrm{~mol} / \mathrm{L} \mathrm{NaNO}_{3}$. The membrane tubing was tightly sealed and placed in $95 \mathrm{~mL}$ of the same electrolyte in a $250 \mathrm{~mL}$ polycarbonate bottle. The bottle was placed on an end-over-end mixer (18 $\mathrm{cm}$ radius, $3 \mathrm{rpm}$ ). The lysate solution was periodically sampled, counted for ${ }^{137} \mathrm{Cs}$-activity, and returned to the reaction vessel. After steady state conditions were achieved (approximately $4 \mathrm{~d}$ ), SAMMS in deionized water were added to the solution outside the dialysis tubing to yield $0.05 \mathrm{~g} / \mathrm{L}$. At selected time intervals, $0.5 \mathrm{~mL}$ of the electrolyte with SAMMS was removed and counted for total ${ }^{137}$ Cs-activity, then returned to the reaction vessel. Additionally, at selected time points, 1.0 $\mathrm{mL}$ of the electrolyte with SAMMS was filtered $(0.2 \mu \mathrm{m})$. The first 8 drops of the filtrate were discarded and $0.5 \mathrm{~mL}$ of the filtrate was collected and counted for aqueous ${ }^{137} \mathrm{Cs}^{+}$-activity. After approximately $9 \mathrm{~d}$, additional SAMMS was added to the suspension to yield $0.25 \mathrm{~g} / \mathrm{L}$. The suspension was sampled as described above.

\subsection{Ion exchange of $\mathrm{Cs}^{+}-\mathrm{Rb}^{+}, \mathrm{Cs}^{+}-\mathrm{NH}_{4}{ }^{+}$, and $\mathrm{Rb}^{+}-\mathrm{Na}^{+}$ on Pristine Sediment}

The ion exchange behavior of $\mathrm{Cs}^{+}$relative to the displacing cations was determined to parameterize the mass action process for development of a kinetic desorption model. The uncontaminated "Above B" sediment was used as an analog to the contaminated one to avoid the interference of other processes in the interpretation of experimental results. Some of the necessary ion exchange data had already been measured [e.g., $\mathrm{Cs}^{+}$$\mathrm{Na}^{+}, \mathrm{Cs}^{+}-\mathrm{K}^{+}$; (Zachara et al., 2002)] and was not repeated here. The "Above B" sediment was treated with $1 \mathrm{~mol} / \mathrm{L}$ sodium acetate $(\mathrm{NaOAc})$ at $\mathrm{pH} 5.0$ (with acetic acid) to remove carbonates and soluble salts (Zachara et al., 2002). The ion exchange behavior of $\mathrm{Cs}^{+}-\mathrm{Rb}^{+}$and $\mathrm{Cs}^{+}-\mathrm{NH}_{4}{ }^{+}$was measured in $0.05 \mathrm{~mol} / \mathrm{L} \mathrm{RbNO}_{3}$ and $0.5 \mathrm{~mol} / \mathrm{L} \mathrm{NH}_{4} \mathrm{NO}_{3}$. The sediments were washed three times in the appropriate electrolyte $\left(\mathrm{Rb}^{+}\right.$or $\mathrm{NH}_{4}{ }^{+}$) and resuspended before addition of $\mathrm{CsNO}_{3}$. The $\mathrm{CsNO}_{3}$ concentrations ranged from $10^{-9}$ to $10^{-1} \mathrm{~mol} / \mathrm{L}$, and were labeled with $7.0 \times 10^{3}$ to $2.0 \times 10^{4} \mathrm{dpm} / \mathrm{mL}^{137} \mathrm{Cs}^{+}$. The ion exchange behavior of $\mathrm{Rb}^{+}-\mathrm{Na}^{+}$was measured in $0.01,0.1$, and $1 \mathrm{~mol} / \mathrm{L} \mathrm{NaNO}_{3}$ electrolytes with $\mathrm{Na}^{+}$-saturated sediment and $\mathrm{a} \mathrm{Rb}^{+}$concentration range of $10^{-9}$ to $10^{-2} \mathrm{~mol} / \mathrm{L}$. An ${ }^{86} \mathrm{Rb}^{+}$ label was used to trace the partitioning of $\mathrm{Rb}^{+}$between the aqueous and solid phases. The suspensions were shaken in 30 $\mathrm{mL}$ Oakridge polycarbonate tubes at $40 \mathrm{rpm}$ and $25^{\circ} \mathrm{C}$ for $16 \mathrm{~h}$. After equilibration, the suspensions were centrifuged and the supernatants were measured for ${ }^{137} \mathrm{Cs}^{+}$and ${ }^{86} \mathrm{Rb}^{+}$activities.

\subsection{Kinetic Studies of Adsorption/Desorption of $\mathrm{Cs}^{+}$on Pristine Sediments}

The NaOAc-treated "Above B" sediment was used to study the kinetics of the short-term $\mathrm{Cs}^{+}$adsorption/desorption process in the absence of secondary mineral products of HLWsediment reaction. The sorption experiments were performed in $0.1 \mathrm{~mol} / \mathrm{L} \mathrm{NaNO}_{3}$ electrolyte spiked with $3.2 \times 10^{-7} \mathrm{~mol} / \mathrm{L}$ $\mathrm{CsNO}_{3}$. The solution was labeled with ${ }^{137} \mathrm{Cs}^{+}$and mixed with $10 \mathrm{~g} / \mathrm{L}$ sediment in a $30 \mathrm{~mL}$ Oakridge polycarbonate tube. The suspensions were equilibrated at room temperature on a bench top shaker at $100 \mathrm{rpm}$. At selected time points, the suspensions were centrifuged and ${ }^{137} \mathrm{Cs}^{+}$was measured as previously described to quantify the time-dependent sorption process.

The $\mathrm{Cs}^{+}$-loaded "Above B" sediments were used for desorption experiments and were mixed with $5 \mathrm{~mol} / \mathrm{L} \mathrm{NaNO}_{3}, 2.9$ $\mathrm{mol} / \mathrm{L} \mathrm{RbNO}_{3}$, and $2.9 \mathrm{~mol} / \mathrm{L} \mathrm{KNO}_{3}$ electrolytes at $50 \mathrm{~g} / \mathrm{L}$ solid concentration. Two sets of desorption experiments were performed. One used the sediments after $1 \mathrm{~d}$ of $\mathrm{Cs}^{+}$adsorption and followed $\mathrm{Cs}^{+}$desorption with time. The other used the sediments after variable days of $\mathrm{Cs}^{+}$adsorption and measured $\mathrm{Cs}^{+}$ desorption after $1 \mathrm{~d}$ equilibration. The equilibration, phase separation, and $\gamma$-counting were performed as described above. 
Table $1 . \mathrm{Cs}^{+}$concentration and cation exchange capacity (CEC) on the contaminated S-SX sediments.

\begin{tabular}{lcccc}
\hline & SX-108-3A & SX-108-7A & 41-09-39-7ABC & 41-09-39-9ABC \\
\hline${ }^{137} \mathrm{Cs}^{+}(\mathrm{pCi} / \mathrm{g})^{\mathrm{a}}$ & $3.420 \times 10^{7}$ & $5.937 \times 10^{7}$ & $4.009 \times 10^{7}$ & $2.195 \times 10^{6}$ \\
$\mathrm{Total} \mathrm{Cs}^{+}(\mu \mathrm{mol} / \mathrm{g}){ }^{\mathrm{b}}$ & $1.366 \times 10^{-2}$ & $2.372 \times 10^{-2}$ & $1.601 \times 10^{-2}$ & $8.768 \times 10^{-4}$ \\
$\mathrm{CEC}\left(\mu \mathrm{Eq} / \mathrm{g}\right.$ of dry sediment) determined using ${ }^{134} \mathrm{Cs}^{+}$ & $49.8 \pm 0.5$ & $74.9 \pm 5.7$ & $61.2 \pm 3.3$ & $46.1 \pm 2.8$ \\
$\mathrm{CEC}\left(\mu \mathrm{Eq} / \mathrm{g}\right.$ of dry sediment) determined using ${ }^{22} \mathrm{Na}^{+}$ & $44.4 \pm 0.7$ & $63.2 \pm 2.7$ & $51.0 \pm 1.7$ & $38.8 \pm 2.6$ \\
Fractional occupation of high-affinity site ${ }^{\mathrm{c}}$ & 0.61 & 0.70 & 0.58 & 0.42 \\
\hline
\end{tabular}

${ }^{a}$ Determined by gamma count, including those in solid and pore-water phases.

${ }^{b}$ Total $\mathrm{Cs}^{+}$calculated based on ${ }^{137} \mathrm{Cs}^{+}$concentrations using Eqns. 1 and 2.

${ }^{\mathrm{c}}$ Calculated based on Cs-CEC and a fraction of high affinity sites to CEC $\left(4.5 \times 10^{-4}\right)$ (Zachara et al., 2002; Liu et al., 2003).

\subsection{Spatial Distribution of Sorbed $\mathrm{Cs}^{+}$in Micas from Pristine Sediment}

Most of the radiocesium in the contaminated sediments (41-09-39) has been previously shown to associate with mica grains (biotite, partially vermiculitized biotite, muscovite) and smectite-cemented clasts (McKinley et al., 2001). Attempts to define a conceptual model for intragrain ${ }^{137} \mathrm{Cs}^{+}$transport by spatially resolved X-ray microprobe measurements of micas separated from the contaminated sediment were unsuccessful because of the low molar adsorbed $\mathrm{Cs}^{+}$concentration (e.g., $<$ $10^{-7} \mathrm{~mol} / \mathrm{g}$ ) of the radioactively contaminated micas. As a surrogate, we hand picked mica grains from the "Above B" composite, contacted these with $10^{-3} \mathrm{~mol} / \mathrm{L} \mathrm{CsNO}_{3}$ solutions, washed them with deionized $\mathrm{H}_{2} \mathrm{O}$, mounted the grains in Buehler petrographic epoxy, and made thin sections (ca. 60 $\mu \mathrm{m})$ parallel to the $\mathrm{C}$-axis. The thin sections were analyzed by $\mathrm{X}$-ray microprobe (XRM) on the GSE-CARS beamline at the Advanced Photon Source (APS), Argonne National Laboratory (details given by McKinley et al., 2001). The observed spatial distribution of $\mathrm{Cs}^{+}$was considered qualitatively representative of the radiocesium distribution in contaminated micas.

\subsection{Data Analysis}

The speciation, activity coefficients, and water activity in the aqueous phase were assumed to be in equilibrium and were calculated for each sample using measured aqueous concentrations and a computerized chemical equilibrium program, GMIN (Felmy, 1995), which incorporated the Pitzer ion-ion interaction model (Pitzer, 1994) and $\mathrm{Cs}^{+}$-electrolyte interaction constants summarized in Liu et al. (2003).

\section{RESULTS}

\section{1. ${ }^{137} \mathrm{Cs}^{+}$Concentration and $\mathrm{CEC}$}

The total ${ }^{137} \mathrm{Cs}^{+}$activities in the HLW-contaminated sediments ranged from $2 \times 10^{6}$ to $6 \times 10^{7} \mathrm{pCi} / \mathrm{g}$ of dry sediment depending on the sample locations (Table 1). The total $\mathrm{Cs}^{+}$ inventory of the sediments includes the $\mathrm{Cs}^{+}$isotopes 133 and 135 that were also part of HLW. The concentrations of different Cs isotopes were quantified by mass spectroscopy (Evans et al., 2001). The relationship between ${ }^{137} \mathrm{Cs}^{+}$and total $\mathrm{Cs}^{+}$concentration in the sediments was:

$$
\mathrm{Cs}_{\text {total }}^{+}(\mathrm{mol} / \mathrm{g})=4.75( \pm 0.18){ }^{137} \mathrm{Cs}^{+}(\mathrm{mol} / \mathrm{g})
$$

The molar concentration is related to the activity of ${ }^{137} \mathrm{Cs}^{+}$by:

$$
{ }^{137} \mathrm{Cs}^{+}(\mathrm{mol} / \mathrm{g})={ }^{137} \mathrm{Cs}^{+}(\mathrm{pCi} / \mathrm{g}) * 2.22 * 365.25 * 24 * 60 * \mathrm{t}_{1 / 2} /
$$$$
\left(\ln 2 * \mathrm{~N}_{\mathrm{A}}\right)
$$

where $\mathrm{t}_{1 / 2}$ (year) is the half-life of ${ }^{137} \mathrm{Cs}^{+}$decay (30.07 yr), and $\mathrm{N}_{\mathrm{A}}$ is the Avogadro constant. The total $\mathrm{Cs}^{+}$concentrations in the sediment samples were calculated by Eqns. 1 and 2 using the measured ${ }^{137} \mathrm{Cs}^{+}$activities (Table 1). $\mathrm{Cs}^{+}$isotopic compositions were also measured in selected supernates from the mass-action desorption experiments, and the desorbed $\mathrm{Cs}^{+}$ pool exhibited the same isotopic ratios as the contaminated sediments (Evans et al., 2001). The concentration of ${ }^{137} \mathrm{Cs}^{+}$ was, therefore, used to trace the behavior of the total $\mathrm{Cs}^{+}$pool. All our reported analyses for ${ }^{137} \mathrm{Cs}^{+}$, therefore, represent $21.05 \%$ of the total $\mathrm{Cs}^{+}$.

The CEC determined using both ${ }^{134} \mathrm{Cs}^{+}$and ${ }^{22} \mathrm{Na}^{+}$on the ${ }^{137} \mathrm{Cs}^{+}$-contaminated sediments ranged from 38.8 to 74.9 $\mu \mathrm{Eq} / \mathrm{g}$ of dry sediment (Table 1 ) and was comparable to that measured on the pristine "Above B" sediments (42.6 to 82.5 $\mu \mathrm{Eq} / \mathrm{g}$ of dry sediment) (Zachara et al., 2002). The CECs (Table 1) determined using ${ }^{134} \mathrm{Cs}^{+}$were consistently higher than using ${ }^{22} \mathrm{Na}^{+}$, possibly due to the incomplete replacement of $\mathrm{Cs}^{+}$and $\mathrm{K}^{+}$in the sediment by $\mathrm{Na}^{+}$in spite of the aggressive washes of the sediments with $\mathrm{Na}^{+}$-electrolyte. A similar problem was noted previously with $\mathrm{K}^{+}$(Zachara et al., 2002).

The sediment ${ }^{137} \mathrm{Cs}^{+}$activity increased with CEC (Table 1). The ratio of the total $\mathrm{Cs}^{+}$concentration $\left({ }^{133} \mathrm{Cs}^{+}+\right.$ ${ }^{135} \mathrm{Cs}^{+}+{ }^{137} \mathrm{Cs}^{+}$) to the CEC (either ${ }^{22} \mathrm{Na}^{+}$or ${ }^{134} \mathrm{Cs}^{+}$) for all samples was less than $3.8 \times 10^{-4}$. This value was less than the fraction of high affinity sites calculated for the "Above B" sediment $\left(4.5 \times 10^{-4}\right)$ (Zachara et al., 2002; Liu et al., 2003). Apparently, adsorbed $\mathrm{Cs}^{+}$was associated primarily with high affinity ion exchange sites in the contaminated sediment. The total sediment $\mathrm{Cs}^{+}$concentrations were $\sim 42$ to $70 \%$ of the high affinity site capacity (Table 1 ).

\subsection{Cation Selectivity Coefficients}

The cation selectivity coefficients $\left(K_{v}\right)$ for the binary exchange of $\mathrm{Rb}^{+}-\mathrm{Na}^{+}, \mathrm{Cs}^{+}-\mathrm{Rb}^{+}$, and $\mathrm{Cs}^{+}-\mathrm{NH}_{4}{ }^{+}$on the "Above B" sediments showed two-site exchange behavior (Fig. 1), as was observed previously (Zachara et al., 2002; Liu et al., 2003). The two-site exchange behavior was consistent with specific $\mathrm{Cs}^{+}$association to edge-interlayer regions of muscovite and biotite, and electrostatic association with vermiculite and smectite (McKinley et al., 2001; Zachara et al., 2002). Ion exchange studies on pure illite also show comparable compositional 


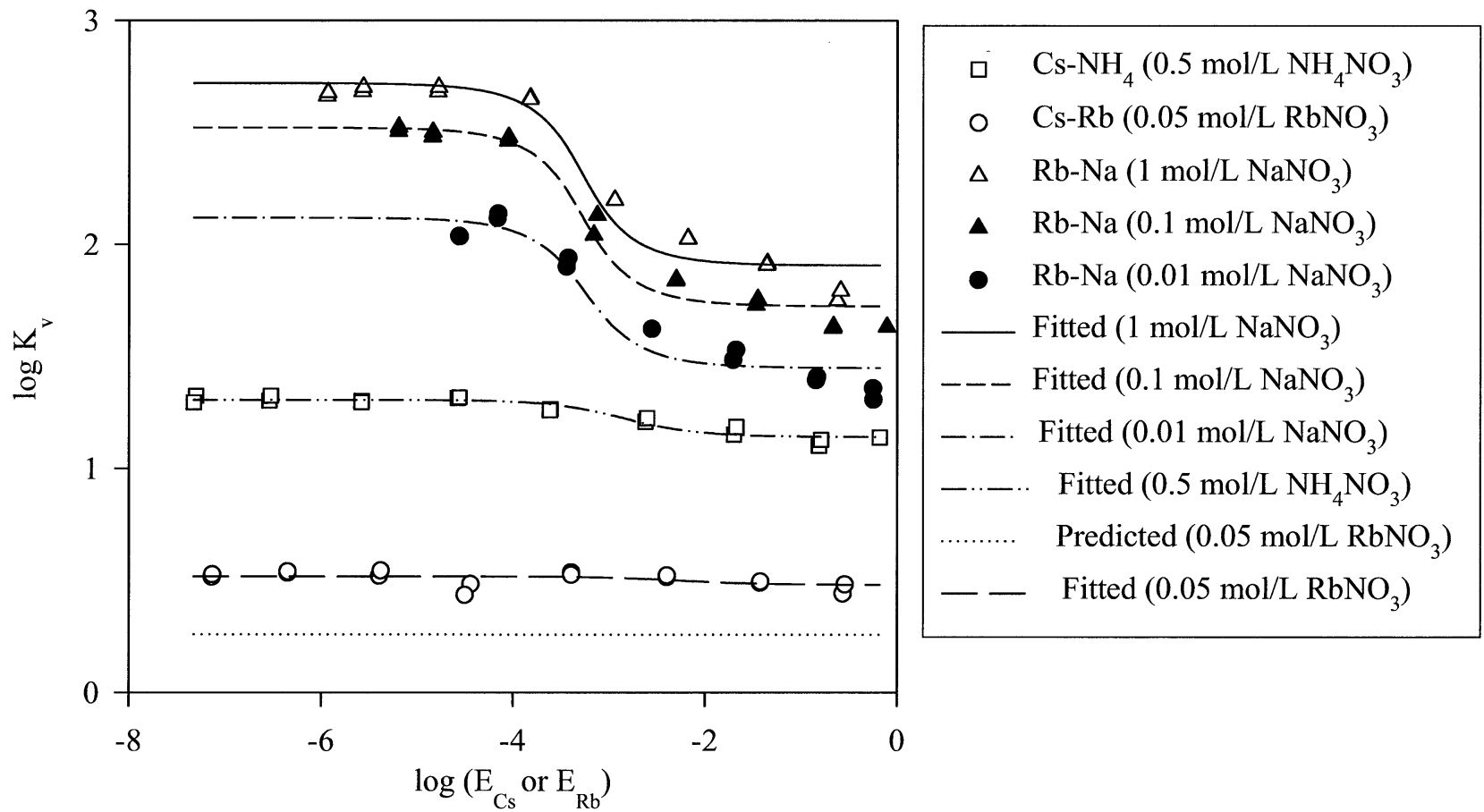

Fig. 1. Experimental and modeling results of cation exchange isotherms for different binary exchange systems. Each isotherm with the same ionic strength was fitted by a two-site model (text) with the fitted selectivity coefficients provided in Table 2. $\mathrm{E}_{\mathrm{Cs}}$ and $\mathrm{E}_{\mathrm{Rb}}$ are the equivalent fraction of $\mathrm{Cs}^{+}$and $\mathrm{Rb}^{+}$, respectively. $\mathrm{E}_{\mathrm{Cs}}$ used for $\mathrm{Cs}-\mathrm{NH}_{4}$ and Cs-Rb exchange, and $\mathrm{E}_{\mathrm{Rb}}$ were used for $\mathrm{Rb}-\mathrm{Na}$ exchange. The selectivity coefficient, $\mathrm{K}_{\mathrm{v}}$, was defined by Eqn. 3 .

dependence and multi-site exchange behavior (Brouwer et al., 1983).

The mass action expression for ion exchange is commonly defined as

$$
\mathrm{uB}_{(\mathrm{aq})}^{\mathrm{v}+}+\mathrm{vAX}_{\mathrm{u}}=\mathrm{uBX}_{\mathrm{v}}+\mathrm{vA}_{(\mathrm{aq})}^{\mathrm{u}+}
$$

where $\mathrm{u}$ and $\mathrm{v}$ are the valences of ionic species $\mathrm{A}$ and $\mathrm{B} ; \mathrm{AX}_{\mathrm{u}}$ and $\mathrm{BX}_{\mathrm{v}}$ are the exchanger phase species $\mathrm{A}^{\mathrm{u}+}$ and $\mathrm{B}^{\mathrm{v}+}$; and $\mathrm{A}^{\mathrm{u}+}$ and $\mathrm{B}^{\mathrm{v}+}$ are the aqueous species. The Vanselow selectivity coefficient $\left(K_{v}\right)$ for the above ion exchange reaction may be defined as:

$$
K_{v}=\left(N_{B}^{u} / N_{A}^{v}\right)\left(\left\{A^{u+}\right\}^{v} /\left\{B^{v+}\right\}^{u}\right)
$$

where $N_{B}$ and $N_{A}$ are the mole fractions of exchanger phase species $\mathrm{B}^{\mathrm{v}+}$ and $\mathrm{A}^{\mathrm{u}+}$; and \{\} denotes activity. The $K_{v}$ is computed from the experimentally measurable conditional constant $\left(K_{\mathrm{c}}\right)$ corrected by aqueous speciation calculation. The conditional constant (for $\mathrm{Cs}^{+}$exchange) is defined as,

$$
K_{c}=\left(N_{C s}^{u} / N_{A}\right)\left(\left[A^{u+}\right] /\left[C s^{+}\right]^{u}\right)
$$

where represents the concentration.

The selectivity coefficients $\left(K_{v}\right.$, Fig. 1$)$ were well described by a two-site exchange model (Table 2 ). The numerical procedures for the model were detailed elsewhere (Zachara et al., 2002). A CEC value of $82.5 \mu \mathrm{Eq} / \mathrm{g}$ and a high affinity site fraction of $4.5 \times 10^{-4}$ were assigned that were consistent with previous studies with this sediment (Zachara et al., 2002; Liu et al., 2003).

The selectivity coefficients for the ion exchange of $\mathrm{Rb}^{+}$for
$\mathrm{Na}^{+}$increased with ionic strength (Fig. 1 and Table 2), as noted for $\mathrm{Cs}^{+}-\mathrm{Na}^{+}$exchange on this same sediment (Liu et al., 2003). The ionic strength dependence is attributed to a water activity effect, and the large difference in ionic hydration energy between exchanging species (Barrer and Klinowski, 1974; Brouwer et al., 1983; Liu et al., 2003). A decrease in water activity at high ionic strength increases the binding energies of cations with low hydration energy, such as $\mathrm{Rb}^{+}$and $\mathrm{Cs}^{+}$, to a greater extent than those with high hydration energy, such as $\mathrm{Na}^{+}$(Eberl, 1980). A thermodynamic model that included such binding energy changes with water activity was developed and applied to laboratory and field data for $\mathrm{Cs}^{+}-\mathrm{Na}^{+}$ exchange in these same S-SX sediments (Liu et al., 2003).

Because of the effects of ionic strength on the $\mathrm{Rb}^{+}-\mathrm{Na}^{+}$ exchange, the experimental results were simulated with a twosite exchange model corrected for the effects of water activity (Liu et al., 2003):

$\log K_{v}^{i}\left(\ln a_{w}\right)=\log K_{e x}^{i}+k \sqrt{-\ln a_{w}} /\left(1+\sqrt{-\ln a_{w}}\right)$

where $a_{w}$ is the water activity; $k$ is a fitting parameter to account for the magnitude of the effects of water activity on exchange selectivity, and $K_{v}^{i}$ and $K_{e x}^{i}$ are the selectivity and exchange constants at site i, respectively. Unlike $K_{v}^{i}, K_{e x}^{i}$ is not a function of composition and electrolyte concentration, and is defined as,

$$
K_{e x}=\left(\left\{B X_{v}\right\}^{u} /\left\{A X_{u}\right\}^{v}\right) /\left(\left\{A^{u+}\right\}^{v} /\left\{B^{v+}\right\}^{u}\right)
$$

where all species are in activity. Eqn. 6 well described the 
Table 2. Selectivity coefficients and exchange constants on Hanford "Above B" sediments.

\begin{tabular}{|c|c|c|c|}
\hline Exchange reaction & Ionic strength $(\mathrm{mol} / \mathrm{L})$ & $\log K_{v}^{\mathrm{I} \text { a }}$ & $\log K_{v}^{\mathrm{II} \mathrm{b}}$ \\
\hline $\mathrm{Rb}^{+}+\mathrm{NaX}=\mathrm{RbX}+\mathrm{Na}^{+}$ & 0.01 & $5.362(0.050)$ & $1.448(0.028)$ \\
\hline $\mathrm{Rb}^{+}+\mathrm{NaX}=\mathrm{RbX}+\mathrm{Na}^{+}$ & 0.10 & $5.793(0.032)$ & $1.723(0.022)$ \\
\hline $\mathrm{Rb}^{+}+\mathrm{NaX}=\mathrm{RbX}+\mathrm{Na}^{+}$ & 1.00 & $5.994(0.043)$ & $1.906(0.035)$ \\
\hline $\mathrm{Cs}^{+}+\mathrm{NaX}=\mathrm{CsX}+\mathrm{Na}^{+}$ & 0.01 & $6.429(0.064)$ & $1.749(0.043)$ \\
\hline $\mathrm{Cs}^{+}+\mathrm{NaX}=\mathrm{CsX}+\mathrm{Na}^{+}$ & 0.10 & $6.820(0.052)$ & $1.979(0.039)$ \\
\hline $\mathrm{Cs}^{+}+\mathrm{NaX}=\mathrm{Cs} \mathrm{X}+\mathrm{Na}^{+}$ & 1.00 & $7.033(0.047)$ & $2.121(0.041)$ \\
\hline $\mathrm{Cs}^{+}+\mathrm{NaX}=\mathrm{CsX}+\mathrm{Na}^{+}$ & 5.00 & $7.239(0.029)$ & $2.302(0.028)$ \\
\hline $\mathrm{Cs}^{+}+\mathrm{KX}=\mathrm{CsX}+\mathrm{K}^{+}$ & 0.01 & $4.503(0.024)$ & $0.891(0.012)$ \\
\hline $\mathrm{Cs}^{+}+\mathrm{KX}=\mathrm{Cs} \mathrm{X}+\mathrm{K}^{+}$ & 0.10 & $4.592(0.024)$ & $0.956(0.008)$ \\
\hline $\mathrm{Cs}^{+}+\mathrm{KX}=\mathrm{CsX}+\mathrm{K}^{+}$ & 1.00 & $4.629(0.024)$ & $1.064(0.009)$ \\
\hline $\mathrm{Cs}^{+}+\mathrm{NH}_{4} \mathrm{X}=\mathrm{CsX}+\mathrm{NH}_{4}^{+}$ & 0.5 & $4.152(0.028)$ & $1.140(0.008)$ \\
\hline $\mathrm{Cs}^{+}+\mathrm{RbX}=\mathrm{CsX}+\mathrm{Rb}^{+}$ & 0.05 & $2.780(0.201)$ & $0.480(0.014)$ \\
\hline Exchange reaction & $k$ & $\log K_{e x}^{\mathrm{I}}$ & $\log K_{e x}{ }^{\mathrm{II}}$ \\
\hline $\mathrm{Cs}^{+}+\mathrm{NaX}=\mathrm{CsX}+\mathrm{Na}^{+}$ & 2.26 & 6.637 & 1.761 \\
\hline $\mathrm{Cs}^{+}+\mathrm{KX}=\mathrm{CsX}+\mathrm{K}^{+}$ & 1.14 & 4.502 & 0.889 \\
\hline $\mathrm{Cs}^{+}+\mathrm{RbX}=\mathrm{CsX}+\mathrm{Rb}^{+}$ & 2.38 & 5.562 & 1.516 \\
\hline
\end{tabular}

${ }^{a}$ High-affinity exchange sites.

${ }^{\mathrm{b}}$ Low-affinity exchange sites.

experimental results of $\mathrm{Rb}^{+}-\mathrm{Na}^{+}$exchange (results not shown, but they were close to the individual fittings in Fig. 1). The best-fit parameters are reported in Table 2. These parameters were determined by simultaneously fitting Eqn. 6 to the three isotherms of $\mathrm{Rb}^{+}$in $\mathrm{Na}^{+}$electrolyte (Fig. 1).

The selectivity coefficients for $\mathrm{Rb}^{+}-\mathrm{Na}^{+}$exchange, together with the previously determined coefficients for $\mathrm{Cs}^{+}-\mathrm{Na}^{+}$exchange (Table 2), allowed us to calculate the coefficients for $\mathrm{Cs}^{+}-\mathrm{Rb}^{+}$exchange, $\log K_{v}{ }_{v}{ }^{\mathrm{I}}(\mathrm{Cs}-\mathrm{Rb})=\log K_{v}{ }^{\mathrm{I}}(\mathrm{Cs}-\mathrm{Na}) \log K_{v}{ }^{\mathrm{I}}$ $(\mathrm{Rb}-\mathrm{Na})=1.039,1027$, and 1.067 and $\log K_{v}{ }^{\mathrm{II}}(\mathrm{Cs}-\mathrm{Rb})=$ $0.215,0.256$, and 0.301 , at $1,0.10 .01 \mathrm{~mol} / \mathrm{L}$ electrolyte concentrations, respectively. Superscripts I and II represent the high and low affinity exchange sites, respectively. These values demonstrated that the ionic strength effect on $\mathrm{Cs}^{+}-\mathrm{Rb}^{+}$exchange was negligible because of the similarity in ionic hydration energies of $\mathrm{Cs}^{+}$and $\mathrm{Rb}^{+}$. These selectivity coefficients were comparable to those estimated on the high and low affinity sites on illite (Brouwer et al., 1983).

We used the calculated selectivity coefficients for $\mathrm{Cs}^{+}-\mathrm{Rb}^{+}$ exchange to predict the $\mathrm{Cs}^{+}$exchange isotherm in $\mathrm{Rb}^{+}$electrolyte (Fig. 1). The prediction consistently underestimated the experimental results in $0.05 \mathrm{~mol} / \mathrm{L} \mathrm{RbNO}_{3}$ electrolyte by up to $0.25 \log$ unit (Fig. 1). The reason for this underprediction was unclear. The best-fit selectivity coefficients for the $\mathrm{Cs}^{+}-\mathrm{Rb}^{+}$ exchange isotherm are summarized in Table 2.

\subsection{Mass Action Effects on ${ }^{137} \mathrm{Cs}^{+}$Desorption}

The amount of ${ }^{137} \mathrm{Cs}^{+}$desorbed after $6 \mathrm{~d}$ of equilibration increased with increasing concentrations of exchanging cations: $\mathrm{Na}^{+}, \mathrm{K}^{+}$, and $\mathrm{Rb}^{+}$. The total desorption extent followed the trend: $\mathrm{Rb}^{+}>\mathrm{K}^{+}>\mathrm{Na}^{+}$(Fig. 2), as expected from the magnitude of the selectivity coefficients (Table 2 ). The amount of the $\mathrm{Cs}^{+}$desorbed in all samples and electrolytes, however, was less than $30 \%$ of the total $\mathrm{Cs}^{+}$on the sediments (Table 3 ).

A desorption ratio $\left(\mathrm{D}_{\mathrm{r}}\right)$ was calculated from the measured 6-d aqueous ${ }^{137} \mathrm{Cs}^{+}$concentration $\left(\left[\left[^{137} \mathrm{Cs}^{+}{ }_{(a q)}\right]_{\text {meas }}\right)\right.$ and a model- predicted equilibrium aqueous ${ }^{137} \mathrm{Cs}^{+}$concentration $\left(\left[{ }^{137} \mathrm{Cs}^{+}{ }_{(\mathrm{aq})}\right]_{\text {equil }}\right)$ based on the total $\mathrm{Cs}^{+}$content of each sample (Table 1): $\mathrm{D}_{\mathrm{r}}=\left[{ }^{137} \mathrm{Cs}^{+}{ }_{(\mathrm{aq})}\right]_{\text {meas }} /\left[{ }^{137} \mathrm{Cs}^{+}{ }_{(\mathrm{aq})}\right]_{\text {equil }}$. The model calculation used the $\mathrm{Cs}^{+}-\mathrm{CEC}$, the site fractions and selectivity coefficients for the "Above B" sediment (Table 2), and exchangeable concentrations of $\mathrm{Na}^{+}$and $\mathrm{K}^{+}$(Table 4, determined from the ammonium oxalate desorption experiments to be discussed subsequently). Ionic strength effects on the selectivity coefficients were corrected using Eqn. 6, and the Pitzer ion-ion interaction model (Pitzer, 1994) was used to calculate the activity of aqueous species. The $D_{r}$ value was less than 0.3 in $\mathrm{K}^{+}$and $\mathrm{Rb}^{+}$electrolyte, but was 0.56 in $5 \mathrm{~mol} / \mathrm{L}$ $\mathrm{NaNO}_{3}$ (Table 3). The calculated ratios indicated that while $\mathrm{K}^{+}$ and $\mathrm{Rb}^{+}$desorbed more ${ }^{137} \mathrm{Cs}^{+}$from the sediment, their end states were further from equilibrium than was the $\mathrm{Na}^{+}$electrolyte system. None of the electrolyte systems achieved equilibrium in $6 \mathrm{~d}$ indicating that $\mathrm{Cs}^{+}$desorption was mass transfer limited.

\section{4. ${ }^{137} \mathrm{Cs}^{+}$Desorption Kinetics from the Contaminated Sediments}

${ }^{137} \mathrm{Cs}^{+}$desorption showed a rapid initial release followed by a slow kinetic process (Fig. 3) in all sediment samples. Replicate solid samples showed excellent reproducibility for samples from borehole SX-108 (e.g., Figs. 3a,b), but less so for samples from borehole 41-09-39 (Figs. 3c,d). The greatest difference between replicates was for the $9 \mathrm{ABC}$ samples in $\mathrm{Rb}^{+}$electrolyte (Fig. 3d). The disparity between the $\mathrm{K}^{+}$and $\mathrm{Rb}^{+}$replicates in sample $7 \mathrm{ABC}$ and $9 \mathrm{ABC}$ was attributed to subsample inhomogeneity (e.g., the replicates varied in their total content of ${ }^{137} \mathrm{Cs}^{+}$by as much as $50 \%$ ). The coarse texture and aggregation status of the 41-09-39 samples, and the very high radioactivity of all the samples, complicated homogenization and subsampling activities. An increase in the displacing cation concentrations from 0.5 to $2 \mathrm{~mol} / \mathrm{L}$ at $47 \mathrm{~d}$ induced another immediate increase of ${ }^{137} \mathrm{Cs}^{+}$desorption (Fig. 3), followed 

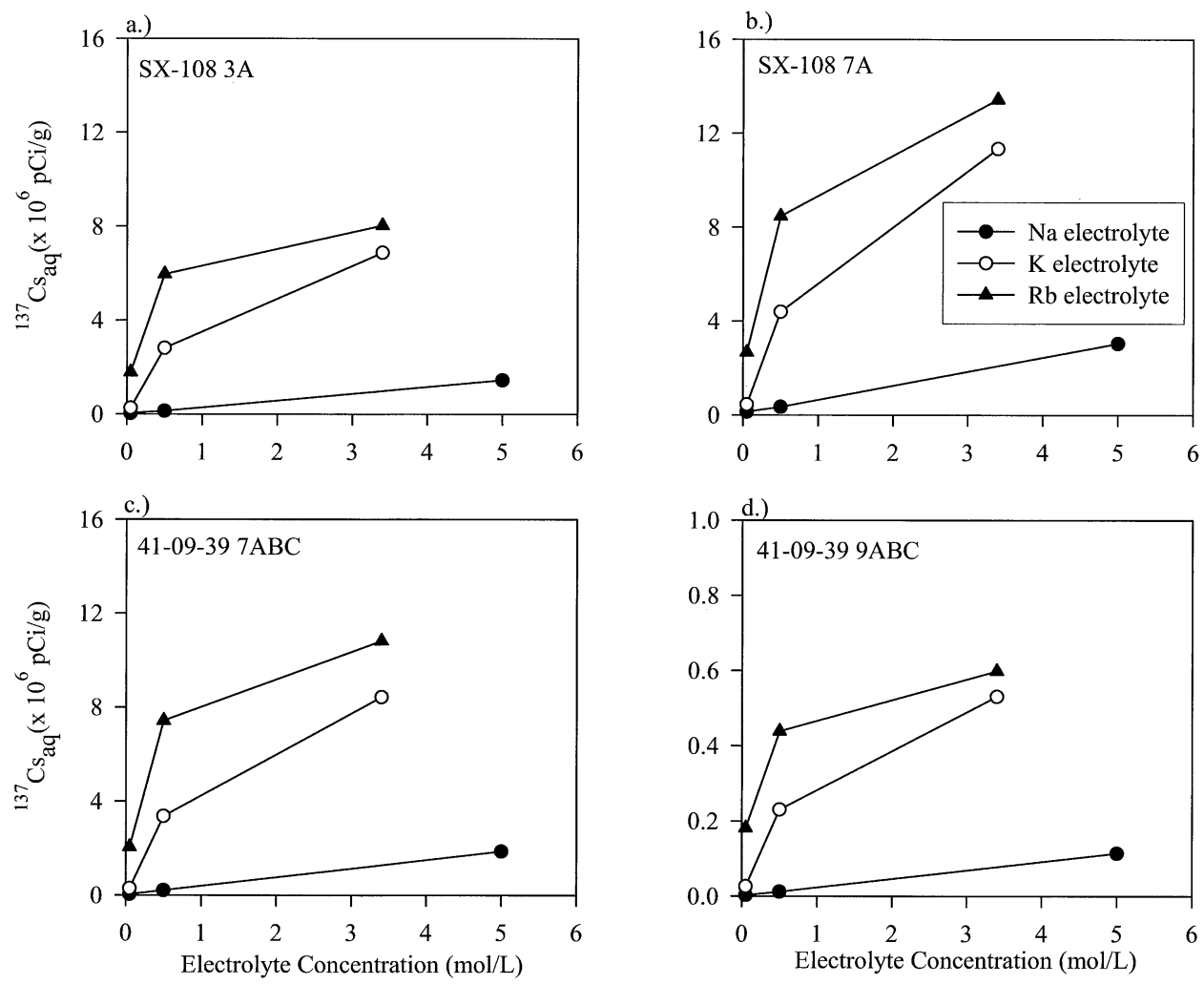

Fig. 2. ${ }^{137} \mathrm{Cs}^{+}$desorption from the ${ }^{137} \mathrm{Cs}^{+}$-contaminated Hanford sediments below the SX tank farm after $6 \mathrm{~d}$ of equilibration as a function of exchanging cations and their concentrations, and sample locations.

again by kinetic desorption. The results indicated that there were at least two pools of ${ }^{137} \mathrm{Cs}^{+}$in the sediments: an equilibrium exchangeable fraction that was immediately responsive to mass action and a mass transfer limited pool. ${ }^{137} \mathrm{Cs}^{+}$desorption from the mass transfer limited pool was slow and continued beyond $67 \mathrm{~d}$ of equilibration.

The initial release of ${ }^{137} \mathrm{Cs}^{+}$was generally higher in $\mathrm{Rb}^{+}$than $\mathrm{K}^{+}$electrolyte, reflecting the stronger selectivity of the sediment exchanger phase for $\mathrm{Rb}^{+}$(Table 2). The second stage of ${ }^{137} \mathrm{Cs}^{+}$ desorption, when the electrolyte concentration was increased to $2.0 \mathrm{~mol} / \mathrm{L}$, was smaller in $\mathrm{Rb}^{+}$electrolyte, suggesting depletion of the exchangeable pool, or possibly edge/interlayer collapse that changed the effective ratio of the exchangeable and mass transfer limited pools. The parallel time dependent behavior in both $\mathrm{Rb}^{+}$ and $\mathrm{K}^{+}$electrolytes indicated that their rates of kinetic desorption were similar. The $\mathrm{D}_{\mathrm{r}}$ value was $0.23-0.31$ in $\mathrm{K}^{+}$and $0.19-0.33$ in $\mathrm{Rb}^{+}$electrolyte. These ratios were comparable to those calculated for the mass action experiments (Table 3 ).

Table 3. The percentage of ${ }^{137} \mathrm{Cs}^{+}$desorbed in $\mathrm{Na}^{+}, \mathrm{K}^{+}$, and $\mathrm{Rb}^{+}$nitrate after contact for 6 days.

\begin{tabular}{|c|c|c|c|c|c|c|c|c|c|}
\hline \multirow[b]{3}{*}{ Concentration $(\mathrm{mol} / \mathrm{L})$} & \multicolumn{9}{|c|}{ Relative to total initial ${ }^{137} \mathrm{Cs}^{+}$on the sediments } \\
\hline & \multicolumn{3}{|c|}{$\mathrm{NaNO}_{3}$} & \multicolumn{3}{|c|}{$\mathrm{KNO}_{3}$} & \multicolumn{3}{|c|}{$\mathrm{RbNO}_{3}$} \\
\hline & 0.05 & 0.5 & .5 & 0.05 & 0.5 & 3.4 & 0.05 & 0.5 & 3.4 \\
\hline SX-108 3A & 0.10 & 0.38 & 4.22 & 0.76 & 8.23 & 20.1 & 5.20 & 17.4 & 23.5 \\
\hline SX-108 7A & 0.23 & 0.58 & 5.12 & 0.74 & 7.40 & 19.1 & 4.50 & 14.3 & 24.3 \\
\hline 41-09-39 7АBC & 0.10 & 0.52 & 4.66 & 0.71 & 8.39 & 21.0 & 5.11 & 18.5 & 27.0 \\
\hline \multirow[t]{3}{*}{ 41-09-39 9ABC } & 0.12 & 0.54 & 5.18 & 1.17 & 10.5 & 24.2 & 8.25 & 20.0 & 27.2 \\
\hline & \multicolumn{9}{|c|}{ Relative to the calculated equilibrium state } \\
\hline & \multicolumn{3}{|c|}{$\mathrm{NaNO}_{3}$} & \multicolumn{3}{|c|}{$\mathrm{KNO}_{3}$} & \multicolumn{3}{|c|}{$\mathrm{RbNO}_{3}$} \\
\hline Concentration $(\mathrm{mol} / \mathrm{L})$ & 0.05 & 0.5 & 5 & 0.05 & 0.5 & 3.4 & 0.05 & 0.5 & 3.4 \\
\hline SX-108 3A & 18.5 & 22.1 & 30.3 & 11.9 & 18.2 & 24.5 & 13.8 & 20.3 & 24.0 \\
\hline SX-108 7A & 15.8 & 22.3 & 43.1 & 11.2 & 19.8 & 25.3 & 14.4 & 20.6 & 23.4 \\
\hline 41-09-39 7ABC & 16.1 & 26.0 & 40.6 & 13.4 & 21.2 & 26.7 & 16.9 & 22.4 & 27.8 \\
\hline 41-09-39 9ABC & 44.7 & 35.6 & 56.4 & 24.6 & 24.0 & 29.8 & 28.5 & 23.1 & 27.9 \\
\hline
\end{tabular}


Table 4. Solutes released from S-SX sediment (in $\mu \mathrm{mol} / \mathrm{g}$ ) in acid ammonium oxalate (AAO).

\begin{tabular}{lcccc}
\hline Element & SX-108-3A & SX-108-7A & 41-09-39-7ABC & 41-09-39-9ABC \\
\hline $\mathrm{Al}^{\mathrm{a}}$ & 207.3 & 211.4 & 145.1 & 145.5 \\
$\mathrm{Ba}^{\mathrm{a}}$ & 0.2627 & 0.3162 & 0.2858 & 0.1569 \\
$\mathrm{Ca}^{\mathrm{a}}$ & 0.1366 & 0.1339 & 0.1276 & 0.1252 \\
$\mathrm{Cr}^{\mathrm{a}}$ & 2.480 & 14.76 & 32.21 & 2.249 \\
$\mathrm{Fe}^{\mathrm{a}}$ & 420.2 & 304.5 & 433.1 & 334.9 \\
$\mathrm{~K}^{\mathrm{a}}$ & 16.26 & 18.16 & 14.91 & 4.211 \\
$\mathrm{~K}^{\mathrm{b}}$ & 7.534 & 5.333 & 67.14 & 4.786 \\
$\mathrm{Mg}^{\mathrm{a}}$ & 62.66 & 67.69 & 180.5 & 57.81 \\
$\mathrm{Na}^{\mathrm{a}}$ & 62.16 & 807.9 & 156.3 & 36.61 \\
$\mathrm{Na}^{\mathrm{b}}$ & 47.53 & 816.6 & 30.90 & 31.92 \\
$\mathrm{Si}^{\mathrm{a}}$ & 32.77 & 33.74 & & 33.19 \\
\hline
\end{tabular}

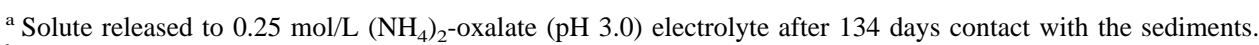

${ }^{\mathrm{b}} \mathrm{Na}^{+}$and $\mathrm{K}^{+}$released after 2 hours of contact with $\left(\mathrm{NH}_{4}\right)_{2}$-oxalate $(\mathrm{pH} 3.0)$ and their concentrations were assumed to be ion exchangeable.

\subsection{Sorbent-Induced $\mathrm{Cs}^{+}$Desorption}

It is possible that high concentration $\mathrm{K}^{+}, \mathrm{NH}_{4}{ }^{+}$, and $\mathrm{Rb}^{+}$ electrolytes may induce collapse of "frayed-edge sites" (FES) where high affinity $\mathrm{Cs}^{+}$exchange is believed to occur (Sawhney, 1972). These particular electrolytes were used to induce $\mathrm{Cs}^{+}$desorption because their large ion exchange selectivities (Table 2) promote high mass-action pressure. However, electrolyte-induced edge collapse may reduce the apparent "exchangeable fraction" of the sorbed $\mathrm{Cs}^{+}$pool. Such a phenomenon may lead to the appearance of poor $\mathrm{Cs}^{+}$desorbability or even fixation, artifactual conclusions related to the electrolyte
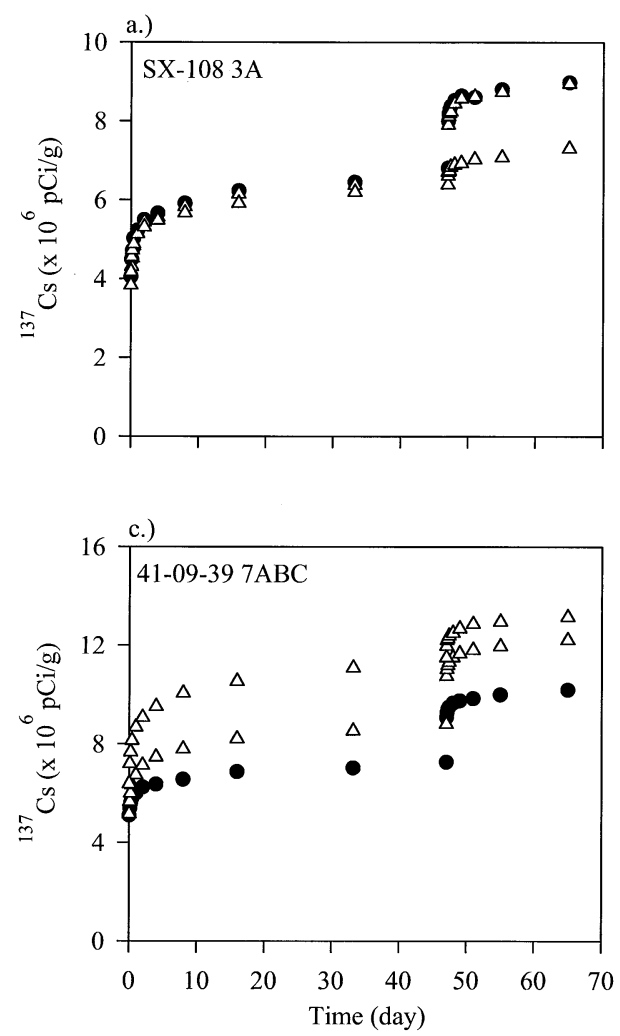

composition. We suspected that such an effect may have limited the mass action response of ${ }^{137} \mathrm{Cs}^{+}$desorption in $\mathrm{Rb}^{+}$ electrolyte ( $2 \mathrm{~mol} / \mathrm{L}$; Fig. 3). The exchangeable fraction of sorbed $\mathrm{Cs}^{+}$may be higher in electrolytes more representative of field pore water that do not promote collapse of high chargedensity phyllosilicate lamellae.

We utilized a highly selective $\mathrm{Cs}^{+}$sorbent (SAMMS) in $\mathrm{Na}^{+}$electrolyte to evaluate the issue of FES-collapse. The SAMMS is a nanocomposite, mesoporous, high surface area material containing immobilized copper ferrocyanide groups with high selectivity for $\mathrm{Cs}^{+}$in $\mathrm{Na}^{+}$electrolyte (Lin et al.,
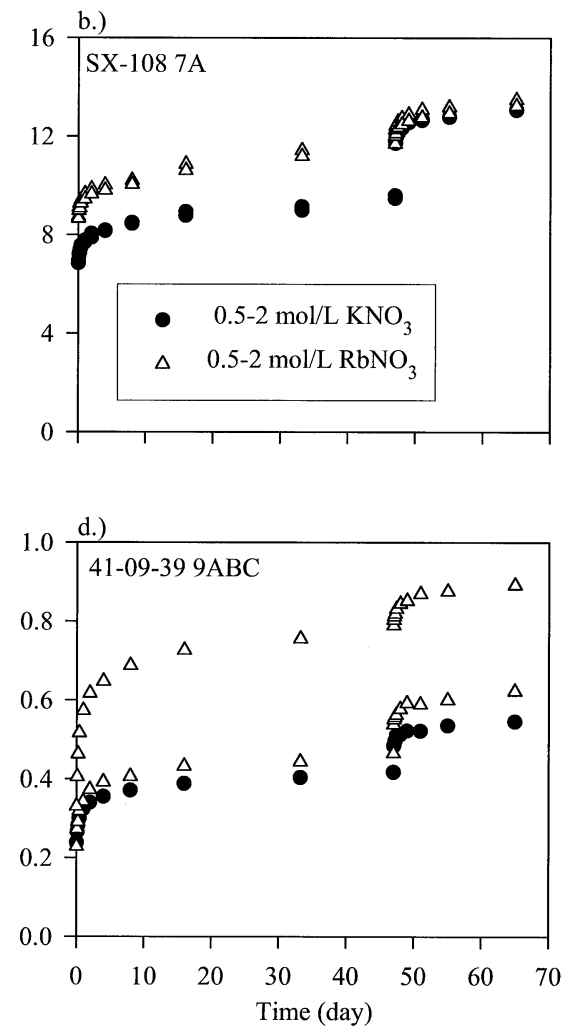

Fig. $3 .{ }^{137} \mathrm{Cs}^{+}$desorption kinetics from the ${ }^{137} \mathrm{Cs}^{+}$-contaminated Hanford sediments below the SX tank farm in 0.5-2.0 $\mathrm{mol} / \mathrm{L} \mathrm{KNO}_{3}$ and $\mathrm{RbNO}_{3}$ electrolytes. 

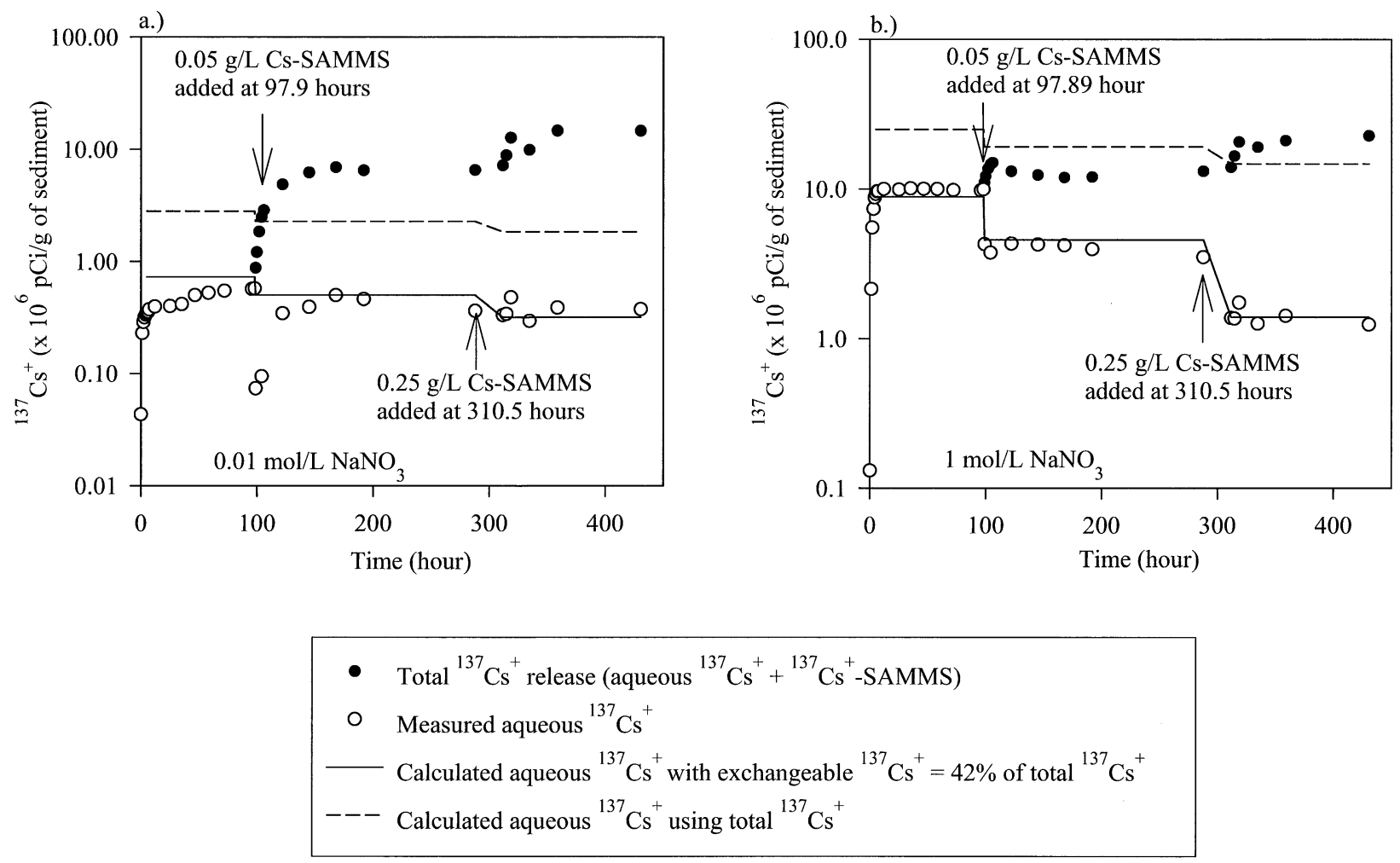

Fig. 4. ${ }^{137} \mathrm{Cs}^{+}$desorption kinetics from the ${ }^{137} \mathrm{Cs}^{+}$-contaminated Hanford sediments below the $\mathrm{SX}$ tank farm in the 0.01 $\mathrm{mol} / \mathrm{L}$ (Fig. 6a) and $1 \mathrm{~mol} / \mathrm{L}$ (Fig. 6b) $\mathrm{NaNO}_{3}$ with/without SAMMS. The SAMMS concentrations were increased from zero to $0.05 \mathrm{~g} / \mathrm{L}$ at $97.9 \mathrm{~h}$, and to $0.25 \mathrm{~g} / \mathrm{L}$ at $310.5 \mathrm{~h}$.

2001). Sodium nitrate electrolytes of two concentrations (1.0 and $0.01 \mathrm{~mol} / \mathrm{L}$ ) were used that fall within the range of those found in pore waters at this site (Serne et al., 2001a,b). The exchanger phases in the contaminated sediment column are primarily $\mathrm{Na}^{+}$-saturated from HLW release.

The addition of the competitive sorbent (SAMMS) significantly increased the total desorption of ${ }^{137} \mathrm{Cs}^{+}$over that observed in $\mathrm{NaNO}_{3}$ electrolyte alone (Fig. 4 compared with Fig. 2b). At low $\mathrm{Na}^{+}$-concentration $\left(0.01 \mathrm{~mol} / \mathrm{L} \mathrm{NaNO}_{3}\right.$, Fig. 4a), the first addition of SAMMS (at $100 \mathrm{~h}$ ) significantly increased the desorption of ${ }^{137} \mathrm{Cs}^{+}$(tot), which was accompanied by a large decrease in ${ }^{137} \mathrm{Cs}^{+}$aqueous concentration. This behavior reflected the rapid adsorption of ${ }^{137} \mathrm{Cs}^{+}$by the SAMMS and the slower release rate from the dialysis bag containing sediment. However, the ${ }^{137} \mathrm{Cs}^{+}{ }_{\text {(aq) }}$ quickly rebounded to its original concentration even though the $\mathrm{Cs}^{+}$site occupation on the SAMMS was only $0.038 \%$ [calculated based on $1.35 \mathrm{mmol}$ $\mathrm{Cs}^{+}$sites/g of SAMMS, (Lin et al., 2001)]. A five-fold increase in the SAMMS concentration (at $310 \mathrm{~h}$ ) doubled the $\mathrm{Cs}^{+}$ desorption (Fig. 4a), with a slight decease in ${ }^{137} \mathrm{Cs}^{+}{ }_{\text {(aq) }}$ The total amount of desorbed ${ }^{137} \mathrm{Cs}^{+}$at experiment termination $(430 \mathrm{~h})$ represented approximately $25 \%$ of the total sorbed ${ }^{137} \mathrm{Cs}^{+}$in the sample.

The behavior of the SAMMS/sediment system was somewhat different in the higher $\mathrm{Na}^{+}$electrolyte ( $1 \mathrm{~mol} / \mathrm{L}$, Fig. 4b). First, the initial ${ }^{137} \mathrm{Cs}^{+}{ }_{(\text {aq }}$ before SAMMS addition was over an order of magnitude higher than in the lower concentration electrolyte because of the mass action effects of $\mathrm{Na}^{+}$. Second,
SAMMS addition promoted small increases in the total desorbed ${ }^{137} \mathrm{Cs}^{+}$concentration, but large decreases in ${ }^{137} \mathrm{Cs}^{+}{ }_{\text {(aq) }}$. At experiment termination, approximately the same amount of ${ }^{137} \mathrm{Cs}^{+}$was desorbed in the low and high $\mathrm{Na}^{+}$experiments.

The concentrations of ${ }^{137} \mathrm{Cs}^{+}{ }_{(\mathrm{aq})}$ rapidly rebounded to apparent steady state conditions after each episode of SAMMS addition in each electrolyte, indicating approximate adherence to a ternary equilibrium state (e.g., solid-liquid-solid). We calculated the expected concentration of ${ }^{137} \mathrm{Cs}^{+}{ }_{(a q)}$ using our two-site equilibrium ion exchange model (selectivity coefficients in Table 2) after subtracting the ${ }^{137} \mathrm{Cs}^{+}$mass sorbed on the SAMMS from the sediment pool and assuming that the residual sediment-sorbed ${ }^{137} \mathrm{Cs}^{+}$was fully exchangeable. These calculations (shown by dashed line in Fig. 4) were higher than the observed concentrations by $0.3-0.6 \log$ units. An excellent agreement with the experimentally observed steadystate ${ }^{137} \mathrm{Cs}^{+}$(aq) concentrations in both electrolytes was obtained with the assumption that $42 \%$ of the ${ }^{137} \mathrm{Cs}^{+}$pool was exchangeable (Fig. 4, solid lines).

The selectivity coefficients (e.g., $\log \mathrm{K}_{\mathrm{v}}$ ) of the SAMMS for $\mathrm{Cs}^{+}-\mathrm{Na}^{+}$exchange were calculated to be 3.37-3.55 in 0.01 $\mathrm{mol} / \mathrm{L}$ and $4.59-4.67$ in $1 \mathrm{~mol} / \mathrm{L} \mathrm{NaNO}_{3}$ based on the measured ${ }^{137} \mathrm{Cs}^{+}{ }_{(\mathrm{aq})}$ concentration and the computed mole fraction occupation of $\mathrm{Cs}^{+}$on the SAMMS. A homogeneous site energy was assumed for the ferrocyanide functional group within SAMMS. The selectivity coefficients of the SAMMS were higher than the low affinity $\mathrm{Cs}^{+}$exchange site in the sediment, but over 2 orders of the magnitude lower than high affinity 
a.)

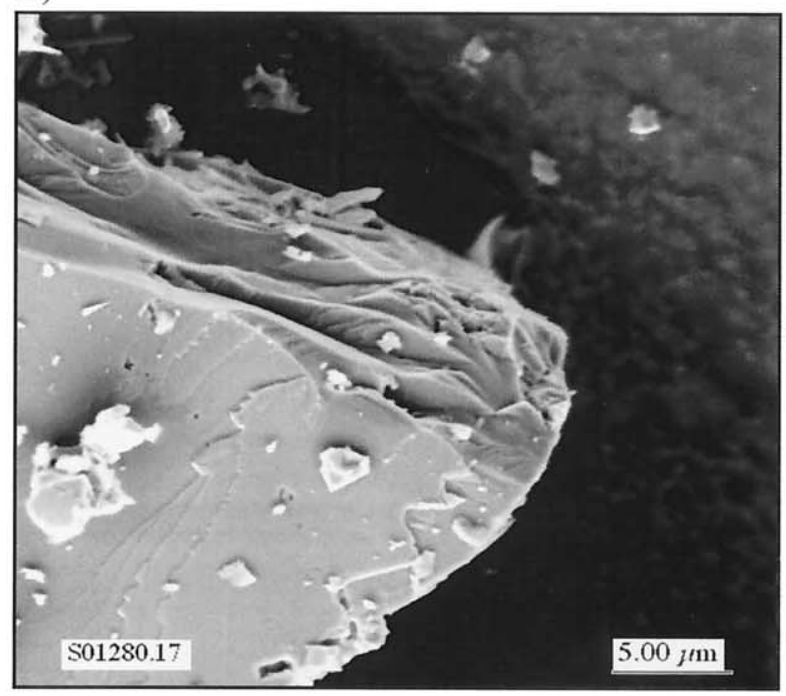

b.)

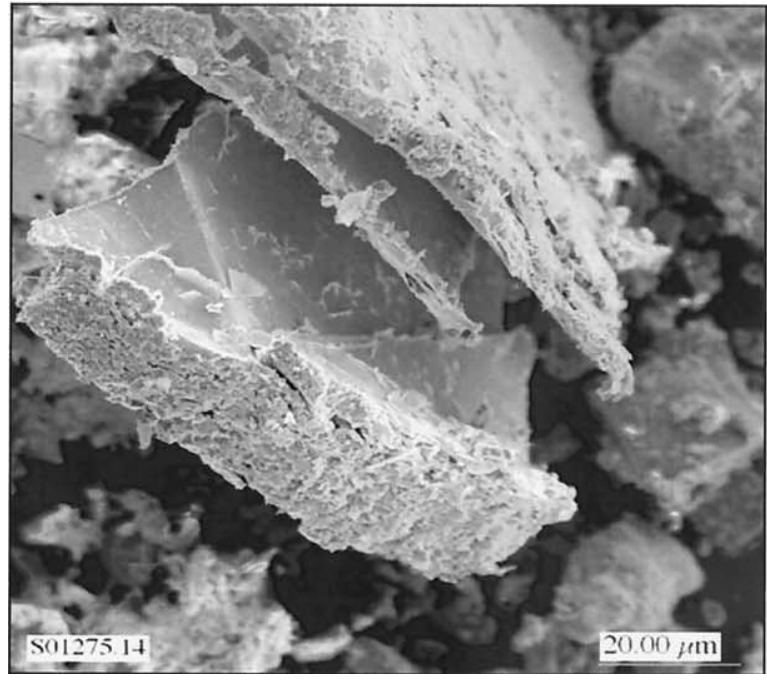

c.)

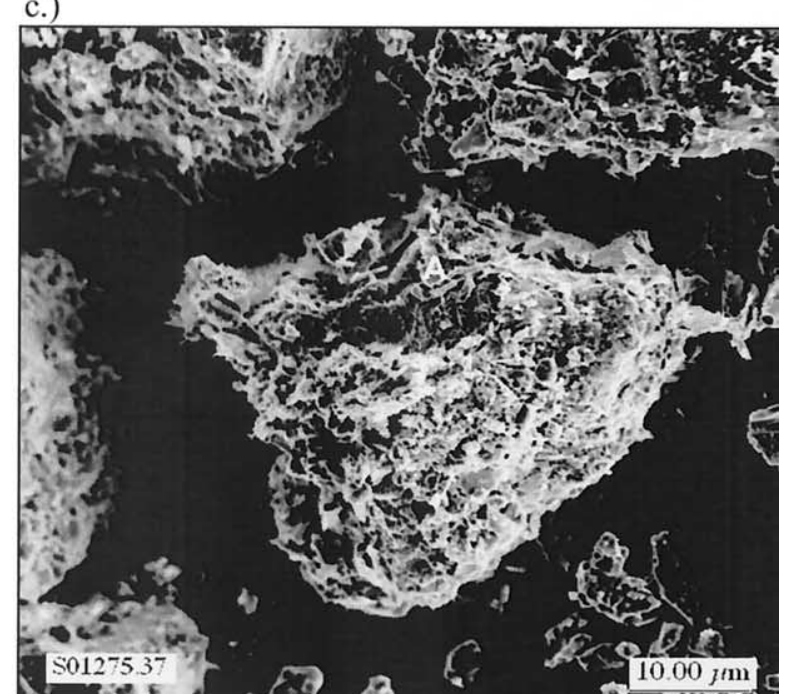

Fig. 5. Scanning electron micrographs of micas isolated from contaminated SX sediment: (a) pristine mica from deep in the sediment column [SX-108, $28.3 \mathrm{~m}$ below ground surface (bgs)]; (b) weakly weathered mica with aluminosilicate precipitates on the edges (sample SX-108 7A, $25.8 \mathrm{~m} \mathrm{bgs}$ ); (c) highly weathered mica with copious secondary mineralization (sample SX-108 3A, $20.6 \mathrm{~m}$ bgs).

sediment site (Table 2). In spite of its lower selectivity coefficients, the SAMMS was able to displace approximately 60$90 \%$ of the computed exchangeable fraction $(42 \%)$ because of a sizable sorption site concentration of the SAMMS.

\section{6. ${ }^{137} \mathrm{Cs}^{+}$Desorption Kinetics in Ammonium Nitrate and Acidified Ammonium Oxalate}

We suspected that poorly crystalline materials may have precipitated subsequent to $\mathrm{Cs}^{+}$adsorption through waste-sediment reaction (the waste stream was high in $\mathrm{OH}^{-}$and $\mathrm{Al}(\mathrm{OH})_{4}{ }^{-}$), and that these secondary phases might effectively armor the surface and block $\mathrm{Cs}^{+}$desorption. Indeed, micas isolated from the contaminated sediment showed evidence for such precipitates. Micas from deep in the contaminated sediment column (28.3 m, Fig. 5a) were clean and identical in appearance to those isolated from pristine sediment. At intermediate depths (25.8 m, SX-108 sample 7A; Fig. 5b) micas retained their original tabular morphology, but showed the presence of surface coatings of fibrous, secondary precipitates. Severe particle alteration was noted in samples collected proximate to the HLW waste source (20.6 m, SX-108 sample 3A; Fig. 5c) where micas were completely encrusted with secondary phases and particle morphology was indistinct. Energy dispersive spectroscopy (EDS) analysis of these precipitates showed the presence of $\mathrm{Na}, \mathrm{Al}, \mathrm{Si}$, and $\mathrm{Fe}$ in variable concentration.

Acidified ammonium oxalate (AAO) dissolves poorly crystalline Al and Fe oxides (Loeppert and Inskeep, 1996), and was used here to remove these phases while simultaneously applying mass action pressure (via the ammonium ion) to desorb ${ }^{137} \mathrm{Cs}^{+}$. Ammonium nitrate, in turn, was used as a control to 

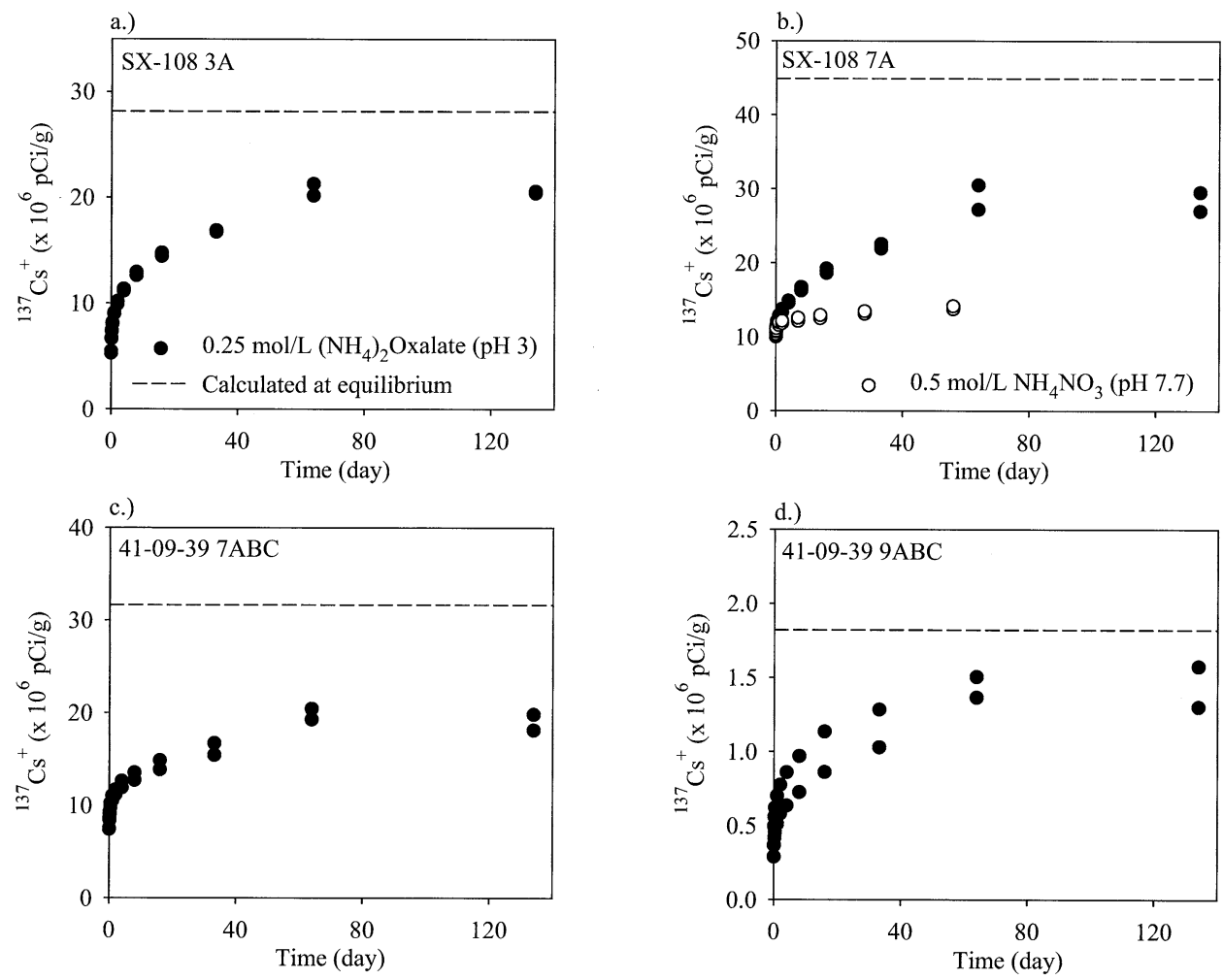

Fig. 6. ${ }^{137} \mathrm{Cs}^{+}$desorption kinetics from the ${ }^{137} \mathrm{Cs}^{+}$-contaminated Hanford sediments below the $\mathrm{SX}$ tank farm in $0.5 \mathrm{~mol} / \mathrm{L}$ $\mathrm{NH}_{4} \mathrm{NO}_{3}$ and $0.25 \mathrm{~mol} / \mathrm{L}\left(\mathrm{NH}_{4}\right)_{2}$-oxalate $(\mathrm{pH} 3)$. The dashed lines were ${ }^{137} \mathrm{Cs}^{+}$desorption in $0.5 \mathrm{~mol} / \mathrm{L} \mathrm{NH}_{4}{ }^{+}$calculated for each sediment at equilibrium using the two-site ion exchange model with measured total $\mathrm{Cs}^{+}$concentration and CEC (Table 1), and the estimated selectivity coefficients (Table 2).

evaluate the extraction potential of the $\mathrm{NH}_{4}{ }^{+}$ion in the absence of proton-promoted dissolution. The kinetic behavior of ${ }^{137} \mathrm{Cs}^{+}$ desorption in $\mathrm{NH}_{4} \mathrm{NO}_{3}(0.5 \mathrm{~mol} / \mathrm{L})$ (Fig. 6b) was similar to that observed in $\mathrm{K}^{+}$and $\mathrm{Rb}^{+}$electrolytes (e.g., Fig. 3b). Although the same quantity of ${ }^{137} \mathrm{Cs}^{+}$was desorbed by $\mathrm{NH}_{4} \mathrm{NO}_{3}$ and AAO in the initial exchange event, the latter extractant significantly enhanced the long-term desorption rate and extent (Fig. $6 b)$. Sample 9ABC, again, showed the worst reproducibility because of its relatively coarse texture. ${ }^{137} \mathrm{Cs}^{+}$desorption in AAO continued for $\sim 65 \mathrm{~d}$ and then ceased. In contrast, $\mathrm{Cs}^{+}$ desorption in $\mathrm{K}^{+}$and $\mathrm{Rb}^{+}$nitrate electrolytes extended over the experimental duration $(>70 \mathrm{~d})$ (Fig. 3), albeit at a slow rate. Measurements of suspension $\mathrm{pH}$ at the termination of AAO experiment averaged 3.25, indicating significant remaining acidity and extraction potential. The desorbed ${ }^{137} \mathrm{Cs}^{+}$concentrations after $63 \mathrm{~d}$ in AAO were averaged for each sediment and were found to represent $63,46,46$, and $64 \%$ of total ${ }^{137} \mathrm{Cs}^{+}$, and $77,61,62$, and $78 \%$ of the calculated ${ }^{137} \mathrm{Cs}^{+}$desorption at exchange equilibrium for sediments $3 \mathrm{~A}, 7 \mathrm{~A}, 7 \mathrm{ABC}$, and $9 \mathrm{ABC}$, respectively.

Acidified ammonium oxalate dissolves poorly crystalline $\mathrm{Fe}(\mathrm{III}) / \mathrm{Al}$ (III) oxides without significant change to coassociated layer silicates if limited to contact times of approximately 2 h (Loeppert and Inskeep, 1996). Significant Fe, Al, and Si were extracted in the first $2 \mathrm{~h}$ (first data point, Fig. 7), consistent with the presence of poorly crystalline $\mathrm{Fe}(\mathrm{III})$ and/or $\mathrm{Al}(\mathrm{III})$ oxides. All of the sediments released comparable quantities of
$\mathrm{Al}$ and $\mathrm{Fe}$ in spite of gross differences in their physical appearances (Fig. 5). The removal of these materials did not significantly increase the initial desorption of ${ }^{137} \mathrm{Cs}^{+}$as shown in Figure $6 \mathrm{~b}$ (e.g., the same initial concentration of ${ }^{137} \mathrm{Cs}^{+}$was desorbed from sample 7A in both $\mathrm{NH}_{4} \mathrm{NO}_{3}$ and $\mathrm{AAO}$ ). With time, the concentrations of dissolved $\mathrm{Al}, \mathrm{Fe}$, and $\mathrm{K}$ continued to increase in almost parallel manner (Fig. 7), consistent with the dissolution of iron-containing expansible [Fe(III)-biedellite] and nonexpansible (biotite, clinochlore) layer silicates known to exist in these sediments. The release profiles of these elements, in turn, paralleled the long-term desorption profiles for ${ }^{137} \mathrm{Cs}^{+}$(Fig. 6), suggesting ${ }^{137} \mathrm{Cs}^{+}$release by dissolution of more soluble phases or structural regions (e.g., frayed edges) in the layer silicate fraction.

\subsection{Kinetics of $\mathrm{Cs}^{+}$Adsorption/Desorption on Pristine Sediment}

The kinetics of $\mathrm{Cs}^{+}$adsorption and desorption on the pristine "Above B" sediment were examined to investigate mass transfer and edge collapse phenomena believed to be important in the desorption behavior from contaminated sediment. The pristine sediment allowed characterization of the short-term adsorption/desorption process in the absence of HLW-induced secondary mineral precipitation.

Cesium sorption to the "Above B" sediment reached an equilibrium state $\left(D_{r}=1\right)$ in less than $10 \mathrm{~d}$ in $0.1 \mathrm{~mol} / \mathrm{L} \mathrm{NaNO}_{3}$ 

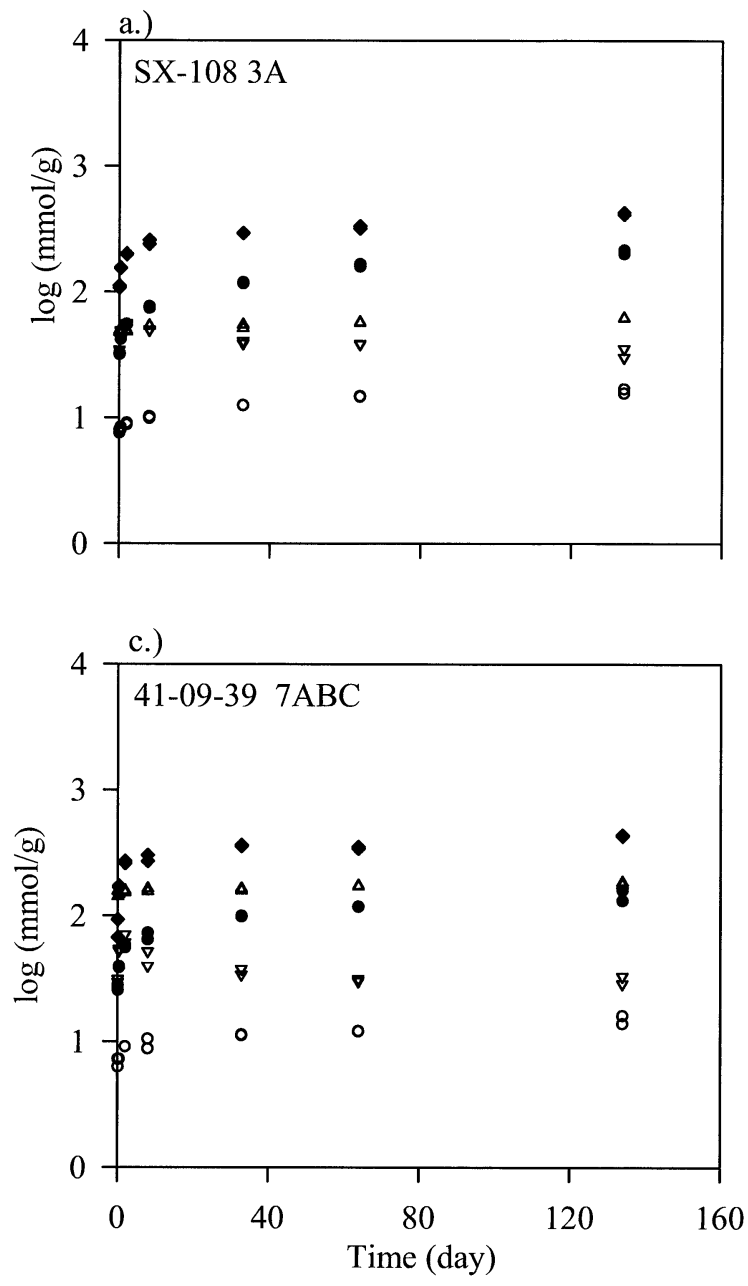

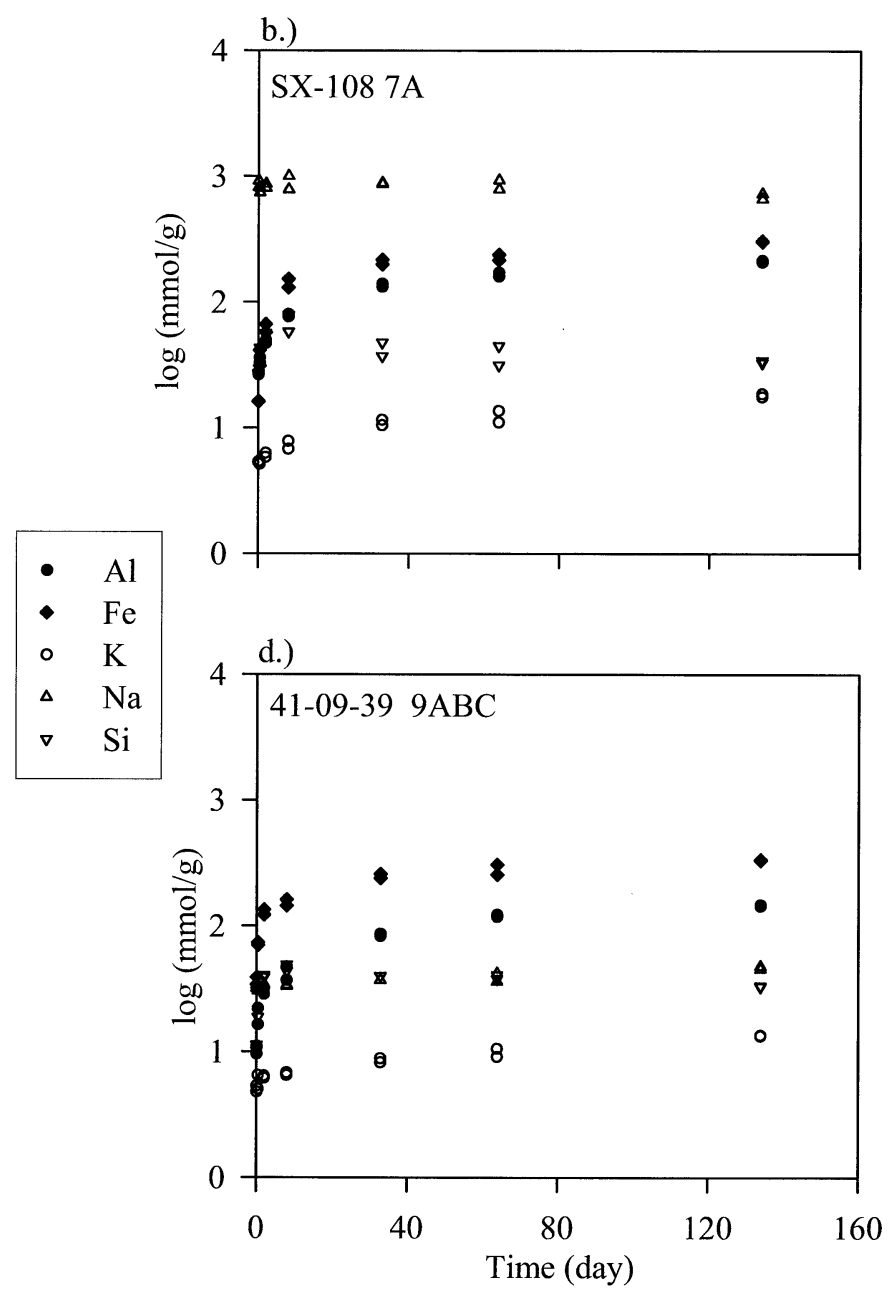

Fig. 7. Solute concentrations accompanying ${ }^{137} \mathrm{Cs}^{+}$desorption from the ${ }^{137} \mathrm{Cs}^{+}$-contaminated Hanford sediments below the SX tank farm in $0.25 \mathrm{~mol} / \mathrm{L}\left(\mathrm{NH}_{4}\right)_{2}$-oxalate (pH 3) (Fig. 3).

(Fig. 8a). The adsorption reaction after $1 \mathrm{~d}$ contact was reversible, with desorption reaching equilibrium (e.g., $\mathrm{D}_{\mathrm{r}}=1$ ) in less than $10 \mathrm{~d}$ after 50 -fold increase in $\mathrm{NaNO}_{3}$ concentration to 4.9 $\mathrm{mol} / \mathrm{L}$ (Fig. 8b). Cesium that had been adsorbed for $27 \mathrm{~d}$ and $70 \mathrm{~d}$ in $0.1 \mathrm{~mol} / \mathrm{L} \mathrm{NaNO}_{3}$ desorbed to the equilibrium state in $24 \mathrm{~h}$ in $4.9 \mathrm{~mol} / \mathrm{L} \mathrm{NaNO}_{3}$ (Fig. 8c). These results contrasted with the contaminated sediments that displayed $\mathrm{D}_{\mathrm{r}}=0.30-$ 0.56 after $6 \mathrm{~d}$

In contrast, desorption extent in $\mathrm{Rb}^{+}$and $\mathrm{K}^{+}$electrolyte was well below the computed equilibrium state regardless of aging time of the sorption complex or desorption period (Figs. 8b,c). The $\mathrm{D}_{\mathrm{r}}$ value was lowest for $\mathrm{Rb}^{+}$, which exhibited the highest mass action pressure given its large selectivity coefficient (Table 2). Desorption was both limited and slow in $\mathrm{K}^{+}$and $\mathrm{Rb}^{+}$ electrolyte after only $1 \mathrm{~d}$ of sorptive contact (Fig. $8 \mathrm{~b}$ ). The increase in desorption with time suggested mass transfer limitations. Also suggestive of mass transfer to intraparticle regions was the decrease in $1-\mathrm{d}$ desorbability in $\mathrm{K}^{+}$and $\mathrm{Rb}^{+}$electrolytes that accompanied aging time of the sorption complex (Fig. $8 \mathrm{c})$. The $\mathrm{D}_{\mathrm{r}}$ value ranged from 0.4 to 0.6 for the pristine sediment after short-term $\mathrm{Cs}^{+}$contact as compared to 0.23 to
0.30 after long-term contact in the contaminated sediments (Table 3).

XRM measurements of the spatial distribution of adsorbed $\mathrm{Cs}^{+}$in mica taken from the pristine sediment after $28 \mathrm{~d}$ of contact with $10^{-3} \mathrm{~mol} / \mathrm{L} \mathrm{CsNO}_{3}$ showed distinct sorptive localization at specific areas on the mica edge (Fig. 9), consistent with the frayed-edge site model of $\mathrm{Cs}^{+}$adsorption (Zachara et al., 2002, and references therein). These micas are the primary radiocesium sorbents in the contaminated sediment (McKinley et al., 2001). Also evident was sorbed $\mathrm{Cs}^{+}$in intraparticle channels parallel to the mica basal plane. The intraparticle distances $(20-50 \mu \mathrm{m})$ are many orders of magnitude beyond the scale attributable to solid-state diffusion. The channels are likely representative of cleavage faces and/or exfoliating mica lamellae. Results (Fig. 9) are shown for muscovite, but analogous findings were observed for biotite (McKinley et al., 2001), which is the more significant radiocesium sorbent (McKinley et al., 2001). These images provide a visual conceptual model of different domains in which mass transfer may be an important control on desorption rate and extent. These include frayed regions on the mica edge susceptible to complex electrolyte- 

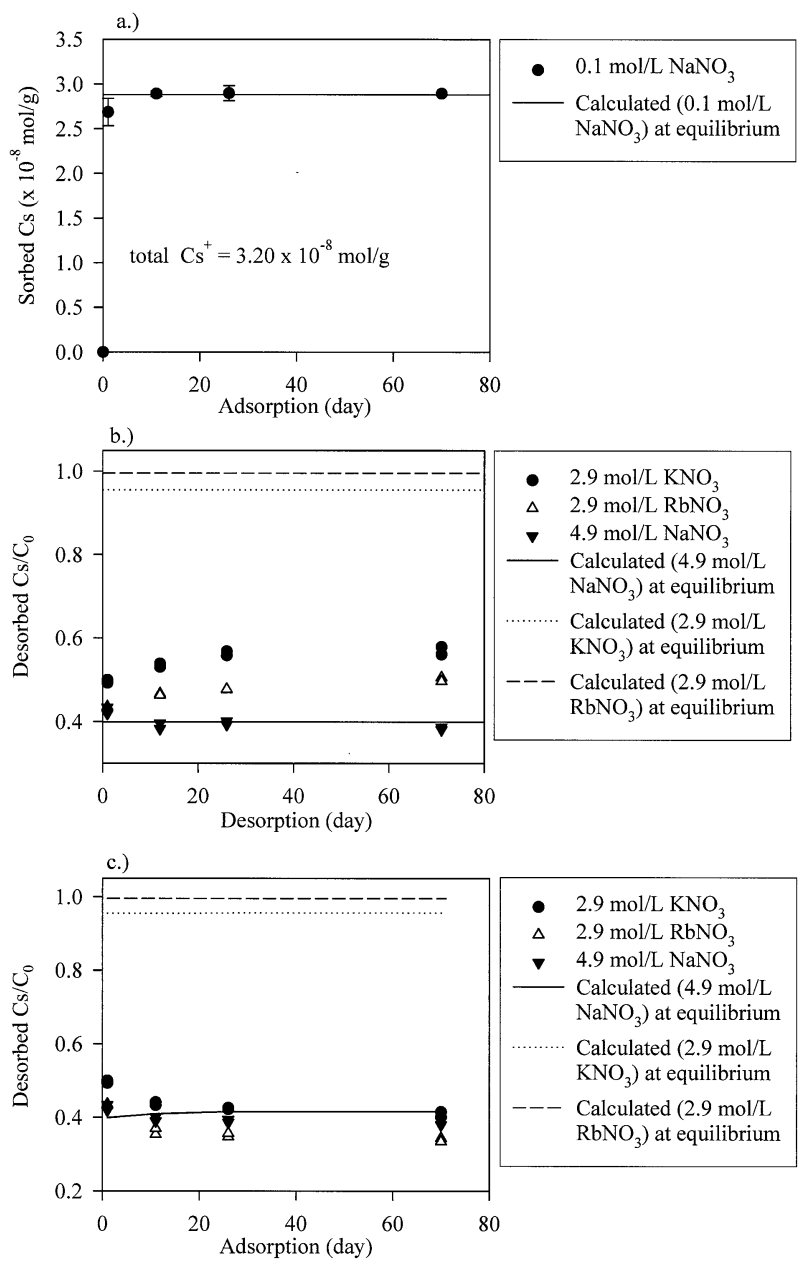

Fig. 8. $\mathrm{Cs}^{+}$adsorption and desorption on pristine Hanford sediment: showing (a) $\mathrm{Cs}^{+}$adsorption kinetics in $0.1 \mathrm{~mol} / \mathrm{L} \mathrm{NaNO}_{3}$; (b) $\mathrm{Cs}^{+}$ desorption kinetics in $4.9 \mathrm{~mol} / \mathrm{L} \mathrm{NaNO}_{3}$ and $2.9 \mathrm{~mol} / \mathrm{L} \mathrm{KNO}_{3}$ or $\mathrm{RbNO}_{3}$ from $\mathrm{Cs}^{+}$-loaded sediments after $1 \mathrm{~d}$ of $\mathrm{Cs}^{+}$adsorption in 0.1 $\mathrm{mol} / \mathrm{L} \mathrm{NaNO}_{3}$ ); (c) $\mathrm{Cs}^{+}$desorption after $1 \mathrm{~d}$ of equilibration in 4.9 $\mathrm{mol} / \mathrm{L} \mathrm{NaNO}_{3}$ and $2.9 \mathrm{~mol} / \mathrm{L}_{\mathrm{KNO}_{3}}$ or $\mathrm{RbNO}_{3}$ from $\mathrm{Cs}^{+}$-loaded sediments (after variable days of adsorption in $0.1 \mathrm{~mol} / \mathrm{L} \mathrm{NaNO}_{3}$ ). The lines were equilibrium concentrations calculated using the two-site ion exchange model.

induced swelling and collapse, and deep intraparticle regions existing along cleavage planes with contact to the aqueous phase. We suggest that this conceptual model applies to micas in the contaminated sediment with the additional complication of the secondary surface precipitates as shown in Figure 5.

\section{DISCUSSION}

\subsection{Desorption Process}

Cesium desorption from the contaminated sediment was a nonequilibrium process characterized by two distinct stages: a rapid initial release followed by a slow kinetic one. The first stage was consistent with ion exchange displacement of $\mathrm{Cs}^{+}$ from fixed charge sites in close communication with the aqueous phase. Observations that, i.) the rapid $\mathrm{Cs}^{+}$desorption increase with exchanging cation concentration (Figs. 2 and 3), and ii.) the total amount of $\mathrm{Cs}^{+}$desorption paralleled the selectivity trend of the electrolyte cations: $\mathrm{Rb}^{+}>\mathrm{K}^{+}>\mathrm{Na}^{+}$ (Fig. 2, Table 3), support this posit. Only a fraction of the adsorbed $\mathrm{Cs}^{+}$was initially exchangeable (e.g., Table 3, Fig. 6), however, and this fraction showed complex dependence on various factors. Application of the two-site ion exchange model (Zachara et al., 2002; Liu et al., 2003) inferred that $10-55 \%$ of the total $\mathrm{Cs}^{+}$was exchangeable depending on the type and concentration of the exchangeable cation and the specific sediment sample. There was no apparent dependence of exchangeability on $\mathrm{Cs}^{+}$adsorption density (e.g., compare 7A and 9ABC in Figs. 2 and 3 and Tables 1 and 3).

The ratio of the total adsorbed $\mathrm{Cs}^{+}$to high affinity exchange sites was $<0.7$ in all the sediments (Table 1), suggesting localization of sorbed $\mathrm{Cs}^{+}$to high affinity exchange sites. Previous work (Zachara et al., 2002) suggests that the high affinity sites reside primarily on weathered mica edges (e.g., Fig. 9), where unique, stereo-selective wedge sites developed (Le Roux et al., 1970). Consistent with this, sorbed radiocesium was observed to associate primarily with micas of different types in these sediments (McKinley et al., 2001). Some spillover of adsorbed $\mathrm{Cs}^{+}$to low affinity sites may have occurred in the contaminated sediments depending on $\mathrm{K}^{+}$adsorption density, but this value is not known with certainty. Given this caveat, our results imply that a significant fraction of the $\mathrm{Cs}^{+}$ adsorbed to the high affinity sites was rapidly exchangeable.

The second, kinetic stage has been attributed to $\mathrm{Cs}^{+}$diffusion from recessed, high affinity edge-interlayer adsorption sites (Comans and Hockley, 1992). The XMP image of $\mathrm{Cs}^{+}$sorbed muscovite from pristine Hanford sediment (Fig. 9) represents one example of the spatial regions where these sites may reside. The short-term kinetic studies with the pristine sediment provided insights on the relative rates of diffusion from these domains in Hanford sediment and the profound impact of electrolyte cation. The desorption (e.g., diffusion) rate was fast in $\mathrm{NaNO}_{3}$, but decreased when $\mathrm{Cs}^{+}$-sorbed, pristine sediment from $\mathrm{NaNO}_{3}$ electrolyte was placed in high concentration $\mathrm{K}^{+}$and $\mathrm{Rb}^{+}$electrolytes (Figs. 8b,c). Implied was rapid edge-interlayer collapse resulting from saturation of the exchange complex with $\mathrm{K}^{+}$and $\mathrm{Rb}^{+}$(Sawhney, 1967, 1969, 1972; Eberl, 1980; Comans et al., 1991). The collapse decreased the amount of adsorbed $\mathrm{Cs}^{+}$that was displaceable by mass action, and as well as the desorption/diffusion rate. Applying our two-site ion exchange model allowed us to conclude that approximately $50 \%$ of the adsorbed $\mathrm{Cs}^{+}$was rendered nonexchangeable in $2.9 \mathrm{~mol} / \mathrm{L} \mathrm{K}^{+}$and $\mathrm{Rb}^{+}$electrolyte. More collapse was implied in $\mathrm{Rb}^{+}$electrolyte (Fig. 8), consistent with its lower hydration energy. Collapse was also implied in the desorption experiments with contaminated sediments by the smaller incremental release that occurred when the $\mathrm{Rb}^{+}$concentrations exceeded $1 \mathrm{~mol} / \mathrm{L}$ (Figs. 2 and 3).

First order rate constants were fit to the concentration data in Figure 3 and Figure 8 after the initial release events to allow comparisons of desorption rates with other published values. The rate constants for $\mathrm{Cs}^{+}$desorption was $\sim 10^{-3}$ $\mathrm{d}^{-1}$ (half-life of $\sim 700 \mathrm{~d}$ ) from both pristine (after $1 \mathrm{~d}$ aging of the sorption complex, Fig. 8b) and the contaminated sediment (first desorption period in Fig. 3). Equivalent first order rate constants for $\mathrm{Cs}^{+}$diffusion into illite intraparticle regions in $\mathrm{K}^{+}$electrolyte were also in the order of $10^{-3} \mathrm{~d}^{-1}$ 


\section{Muscovite Section}
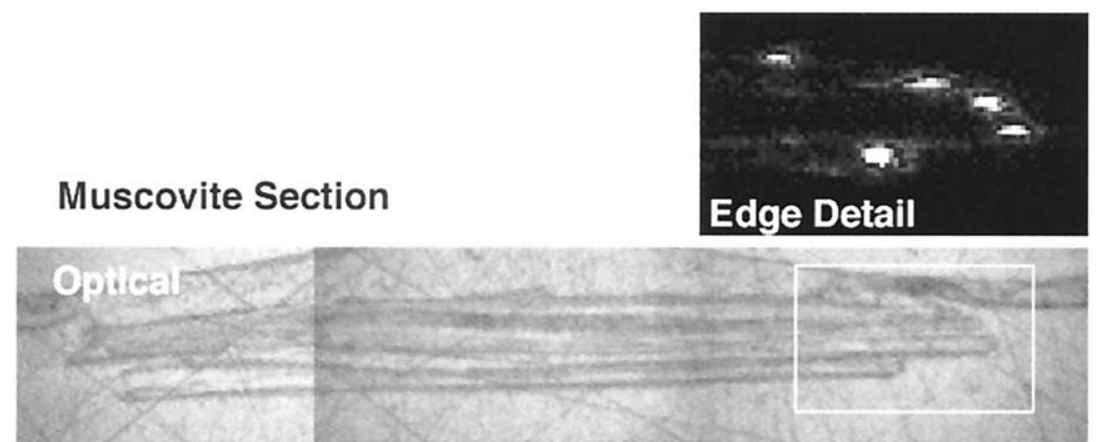

\section{Normal Brightness}
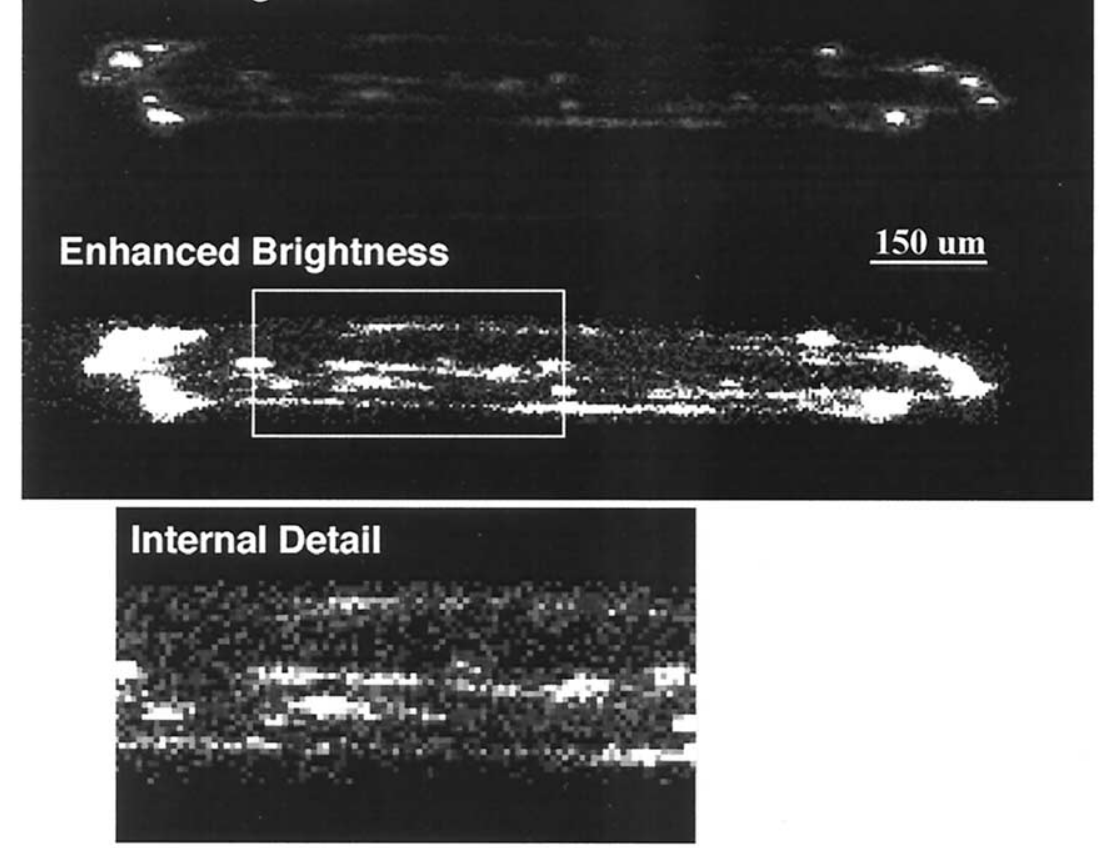

Fig. 9. X-ray microprobe images of $\mathrm{Cs}^{+}$-loaded muscovite flake: showing the ${ }^{137} \mathrm{Cs}^{+}$distribution on edges and also intraparticle channels parallel to the mica basal plane.

(Comans and Hockley, 1992). In contrast, the estimated rate constant for pristine Hanford sediment in $\mathrm{NaNO}_{3}$ was $0.3 \mathrm{~d}^{-1}$ (half-life of $2.3 \mathrm{~d}$ ), which underscored the rapid and unique desorption behavior for $\mathrm{Cs}^{+}$in that specific experimental system.

The apparent exchangeability and long-term kinetic release rates of sorbed $\mathrm{Cs}^{+}$were different in the pristine and contaminated sediments. We originally believed that this difference could result from the presence of the secondary precipitates that so obviously coated mineral grains in the contaminated samples (Figs. 5b,c). Such precipitates might veneer the surfaces, preventing water or electrolyte exchange. Desorption experiments were performed in AAO to evaluate such effects. The results of these experiments showed no difference in the rapidly exchangeable fraction after $2 \mathrm{~h}$ of extraction (e.g., Fig. 6b), the time period deemed appropriate for removal of poorly crystalline oxides. Thus, the secondary precipitates did not appear to influence the exchangeable fraction of adsorbed $\mathrm{Cs}^{+}$and/or the amount of $\mathrm{Cs}^{+}$release in the first stage of desorption. However the rate and extent of the long-term desorption process was markedly increased by continued contact with AAO. Exposure to AAO in excess of $2 \mathrm{~h}$ can promote layer silicate dissolution, and the continued increase in supernatant $\mathrm{K}^{+}$and $\mathrm{Al}^{3+}$ implied such reaction. The enhanced long-term release may be attributed to two factors: i) the removal of surface coatings relieved mass-transport impediments at the mica-water interface allowing for greater diffusive flux from internal channels and pore spaces, or ii) time-variant dissolution of high surface area mica edge regions released sorbed $\mathrm{Cs}^{+}$from collapsed high-affinity site domains. Although our study cannot discriminate between these two mechanisms, we feel the latter explanation is supported by the approximately parallel rates of evolution of $\mathrm{K}^{+}$, $\mathrm{Al}^{3+}$, and $\mathrm{Cs}^{+}$from 1 to $70 \mathrm{~d}$.

\subsection{Modeling Nonequilibrium Desorption}

Nonequilibrium $\mathrm{Cs}^{+}$ion exchange has been modeled using coupled sequences of kinetic steps (Liu et al., 1994), and coupled equilibrium exchange with a first-order approximation to the diffusive process (Comans and Hockley, 1992). The former approach assumed that $\mathrm{Cs}^{+}$ion exchange consisted of 3 


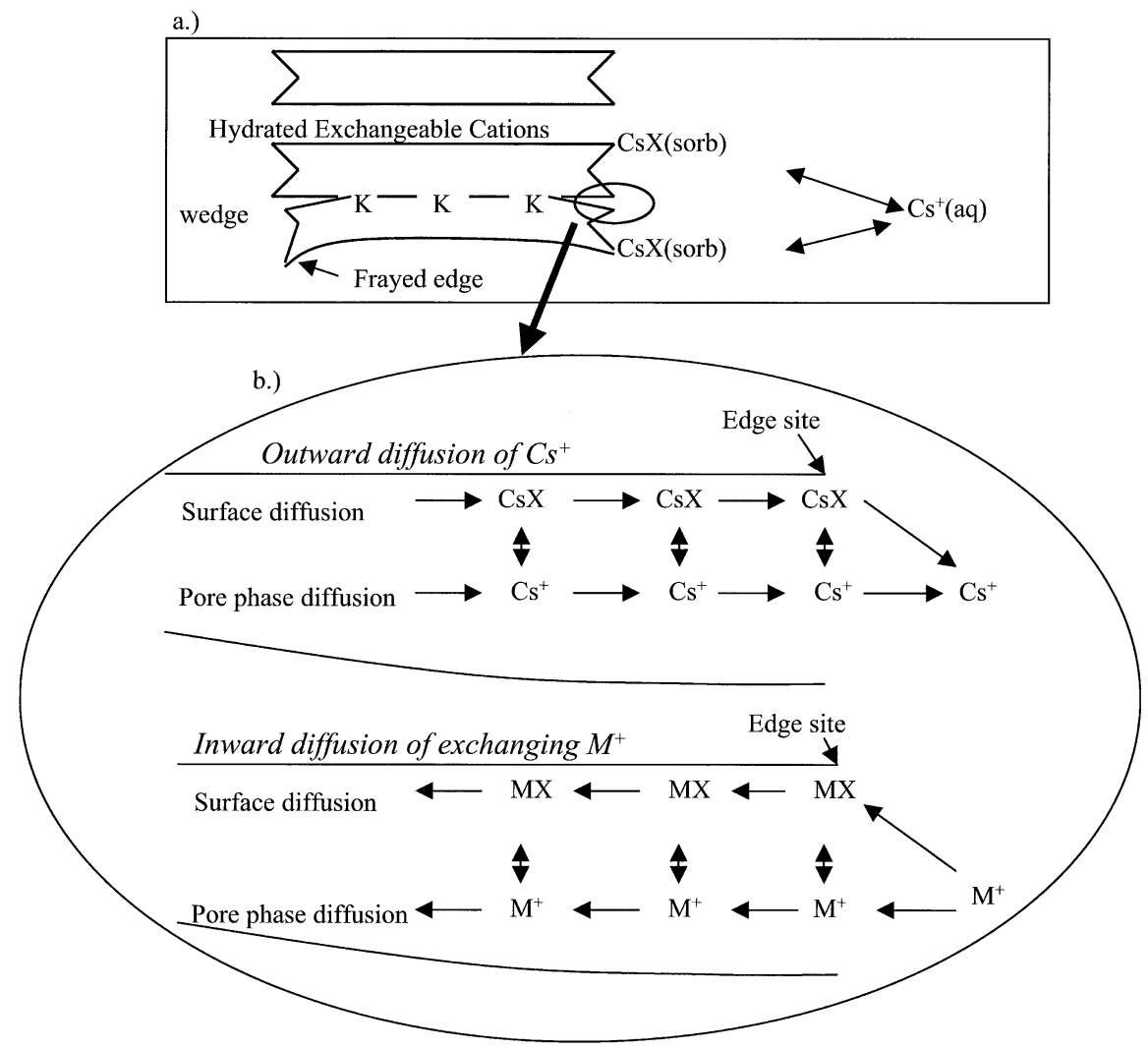

Fig. 10. Schematic diagram of Cs exchange between external edge sites and aqueous phase (Fig. 10a), and diffusion and exchange within the edge-interlayer regions (Fig. 10b).

different kinetic steps: i) film diffusion between the aqueous and solid phase, ii) a kinetic sorption reaction at the surface, and iii) intraparticle diffusion from external to internal adsorption sites. Differential site energetics was not considered and the individual kinetic steps required discrete characterization (Sposito, 1994), which was found to be difficult. The second approach separated exchange sites into two or three boxes (Comans and Hockley, 1992). In the two-box model, ion exchange was assumed to be kinetic; ion exchange in the first box was reversible and connected to the second box, where ion exchange was allowed slow reversibility (months and years) (Cowan et al., 1991). The three-box model consisted of the two-box model, supplemented by an additional box where ion exchange was in equilibrium with the aqueous phase. The kinetic processes in both the two-box and three-box models were approximated by first-order models and equilibrium exchange was modeled using the Freundlich isotherm.

The experimental observation of a two stage desorption process (Figs. 3 and 8) combined with $\mathrm{Cs}^{+}$sorptive localization at specific edge regions and internal channels (Fig. 9) lead us to propose the descriptive model in Figure 10. The model includes equilibrium ion exchange on external surface sites (Fig. 10a) and counter-current $\mathrm{Cs}^{+}-\mathrm{M}^{+}$(exchanging cation) diffusion into/from edge-interlayer regions. A slab diffusion model was assumed because of the layer characteristics of ${ }^{137} \mathrm{Cs}^{+}$distribution on the edge and within the intraparticle region (Fig. 9). For ease of discussion, the edge-interlayer sites exhibiting kinetic or diffusion-limited sorption are considered intraparticle sites. The model for intraparticle sites was described as follows:

$\mathrm{Cs}^{+}$diffusion:

$$
\begin{aligned}
& \frac{\partial q_{C s}}{\partial t}=D_{p}^{C s} \frac{\partial}{\partial x}\left(\varepsilon_{p}(x) \frac{\partial\left[C s^{+}\right]_{a q}^{i n}}{\partial x}\right) \\
& +\rho_{s} D_{s}^{C s} \frac{\partial}{\partial x}\left(\left(1-\varepsilon_{p}(x)\right) \varphi(x) \frac{\partial[C s X]^{i n}}{\partial x}\right)
\end{aligned}
$$

Exchanging cation diffusion:

$$
\begin{aligned}
& \frac{\partial q_{M^{+}}}{\partial t}=\varepsilon_{p} D_{p}^{M} \frac{\partial}{\partial x}\left(\varepsilon_{p}(x) \frac{\partial\left[M^{+}\right]_{a q}^{i n}}{\partial x}\right) \\
& +p_{s} D_{s}^{M} \frac{\partial}{\partial x}\left(\left(1-\varepsilon_{p}(x)\right) \varphi(x) \frac{\partial[M X]^{i n}}{\partial x}\right)
\end{aligned}
$$

Equilibrium cation exchange on intraparticle sites:

$$
[C s X]^{i n}=\frac{K_{v}^{i n}\left\{C s^{+}\right\}_{a q}^{i n} \varphi(x)}{\left\{M^{+}\right\}_{a q}^{i n}+K_{v}^{i n}\left\{C s^{+}\right\}_{a q}^{i n}}
$$

where $\left[C s^{+}\right]_{a q}^{i n}$ and $\left\{C s^{+}\right\}_{a q}^{i n}$, and $\left[M^{+}\right]_{a q}^{i n}$ and $\left\{M^{+}\right\}_{a q}^{i n}$ are the aqueous concentrations and activities of $\mathrm{Cs}^{+}$and exchanging cation $\mathrm{M}^{+}$in the intraparticle pores, respectively; $q_{C s+}$ and $q_{M+}$ are the total concentrations (aqueous + sorbed); $\mathrm{D}_{\mathrm{p}}{ }^{\mathrm{i}}$ and 
$\mathrm{D}_{\mathrm{s}}{ }^{\mathrm{i}}$ are the diffusivities for aqueous and sorbed species $\mathrm{i}$, respectively; $[\mathrm{CsX}]^{\mathrm{in}}$ and $[\mathrm{MX}]^{\mathrm{in}}$ are the equivalent fraction of sorbed species of $\mathrm{Cs}^{+}$and $\mathrm{M}^{+}$on intraparticle sorption sites, respectively; $\varepsilon_{\mathrm{p}}(x)$ is the intraparticle porosity; $\rho_{\mathrm{s}}$ is the solid density; and $\varphi(x)$ is the intraparticle sorption site density.

Eqns. 8-10, when coupled with two-site equilibrium ion exchange on external sites at the aqueous-solid boundary, is a mathematically complete diffusion problem. However, the problem solution requires microscopic information, including the intraparticle porosity, the intraparticle site density, and aqueous and surface diffusivities of both $\mathrm{Cs}^{+}$and exchanging cations in the intraparticle regions. These properties are difficult to measure and therefore, the model required simplification to be tractable. Considering that the intraparticle porosity is usually small (Ball and Roberts, 1991) and that $\mathrm{Cs}^{+}$strongly adsorbs to edge-interlayer sites (Sawhney, 1967, 1969, 1972; Eberl, 1980), we assumed that the $\mathrm{Cs}^{+}$mass associated with the intraparticle aqueous phase was negligible compared to the sorbed phase. With this assumption and considering cases when surface diffusion was the rate-limiting process, the intraparticle problem defined by Eqns. 8-10 was simplified to one equation:

$$
\frac{\partial q_{C s}}{\partial t} \approx \rho_{s} \varphi(Y) \frac{\partial[C s X]^{i n}}{\partial t}=\rho_{s}\left(D_{s}^{C s} / L^{2}\right) \frac{\partial}{\partial Y}\left(\varphi(Y) \frac{\partial[C s X]^{i n}}{\partial Y}\right)
$$

where $\mathrm{y}$ is a dimensionless variable, $\mathrm{Y}=\mathrm{x} / \mathrm{L}$ (diffusion distance $\mathrm{x}$ normalized by an average intraparticle diffusion length, L).

Surface diffusion has been proposed as a rate-limiting process in the intraparticle diffusion of $\mathrm{Cs}^{+}$in clayey soils (Liu et al., 1994). Rigorous characterization of surface diffusion, however, is rarely achieved because of the difficulty in experimentally distinguishing aqueous and surface diffusion (Cussler, 1995). The assumption that either aqueous or surface diffusion is the rate-limiting process is often used to simplify the mathematical mass transport problem (such as Eqns. 8-10) and to avoid difficult characterization of the individual diffusive processes (Cussler, 1995; Do, 1998). In such cases, the experimentally determined diffusion parameter, such as $D_{s}$ in Eqn. 11 , is an apparent one (Do, 1998), lumping the potential effects of both processes.

In the following analysis, we used Eqn. 11 instead of Eqns. 8-10 to describe $\mathrm{Cs}^{+}$diffusion because of its simplicity and minimal number of parameters. The parameters in Eqn. 11 include the lumped effects of both aqueous and surface diffusion in the intraparticle regions as described by Eqns. 8-10. The boundary conditions for Eqn. 11 were formulated as:

$\left.[C s X]^{i n}\right|_{Y=0}=[C s X]^{e q, H A}(t) ;\left.\frac{\partial[C s X]^{i n}}{\partial Y}\right|_{Y=1}=0 ; 0 \leq t<$

$+\infty$

where $[C s X]^{e q, H A}(t)$ is the equivalent fraction of sorbed $\mathrm{Cs}^{+}$on the equilibrium, high affinity sites presumed to exist on the mica edge. A no mass flux condition was used at the internal end of the intraparticle pore channel. The initial condition was generally taken as:

$$
\left.[C s X]^{i n}\right|_{t=0}=f(Y) ; 0 \leq Y \leq 1
$$

The numerical solution to Eqn. 11 that was constrained by the conditions of Eqn. 12 and 13 was coupled with the equilibrium two-site ion exchange model applied to external sites. The problem was solved by a sequential iteration approach at each time step through the boundary condition at the edge site (Eqn. 12). A fully backward finite difference scheme was used in solving Eqn. 11. The parameter, $D_{s}^{C s} / L^{2}$, in Eqn. 11 was lumped as a fitting parameter because of the difficulty in determining a unique value for the diffusion length. The intraparticle site density, $\varphi(\mathrm{Y})$, was assumed to be a hyperbolic function, with higher site density near the solid surface and lower density toward the inside of intraparticle pore channel:

$$
\varphi(Y)=\frac{a}{b+Y}
$$

The fitting parameters a and $\mathrm{b}$ were related by the following constraint:

$$
\int_{0}^{1} \varphi(Y) d Y=E^{i n} C E C
$$

where $E^{\text {in }}$ is the equivalent fraction of intraparticle sorption sites in term of the total sediment CEC. The intraparticle site density function (Eqn. 14) was not experimentally measured, but may be a function of particle size, interlayer and edge weathering degree, $\mathrm{Fe}$ (II/III) content of the mica, the lumped effects of intraparticle pore channels with different length and tortuosity, and other as yet undefined properties. Although the higher site density near the surface was supported by the XRM analyses (bright spots in Fig. 9), the continuous hyperbolic decrease of site density toward particle interior was a mathematical simplification that seemed justifiable.

The diffusion model well described $\mathrm{Cs}^{+}$adsorption and desorption behavior on the uncontaminated Hanford sediment in $\mathrm{NaNO}_{3}$ electrolyte (Fig. 11). Three parameters: diffusivity $\left(D_{s}^{C s} / L^{2}\right)$, the shape parameter of the site density function (b), and the ratio of external to intraparticle high affinity sites $\left(\mathrm{E}^{\text {ext }} / \mathrm{E}^{\mathrm{in}}\right)$, were used to simultaneously fit all experimental results in Figure 11. The total CEC $(82.5 \mu \mathrm{Eq} / \mathrm{g})$ and the fraction of high affinity sites $\left(4.5 \times 10^{-4}\right)$ were fixed at previously determined values (Zachara et al., 2002; Liu et al., 2003). The selectivities of both internal and external sorption sites were assumed to be identical. The assumed hyperbolic site density function was found necessary to simulate the experimental results of Figure 11c. The best-fit parameters (Table 5) implied that: 1) more than half of the high affinity sites were subjected to the kinetic process, 2) internal site density was much higher near the mineral surface and rapidly decreased into the intraparticle region, and 3) diffusion from the intraparticle region was fast in $\mathrm{NaNO}_{3}$ electrolyte.

The fitted parameters from $\mathrm{NaNO}_{3}$ electrolyte, however, significantly over-predicted the $\mathrm{Cs}^{+}$desorption in $\mathrm{KNO}_{3}$ and $\mathrm{RbNO}_{3}$ electrolytes (Fig. 12). Both the diffusion parameter and the ratio of external to intraparticle sites had to be reduced to fit the experimental results (Table 5). The results suggested that 

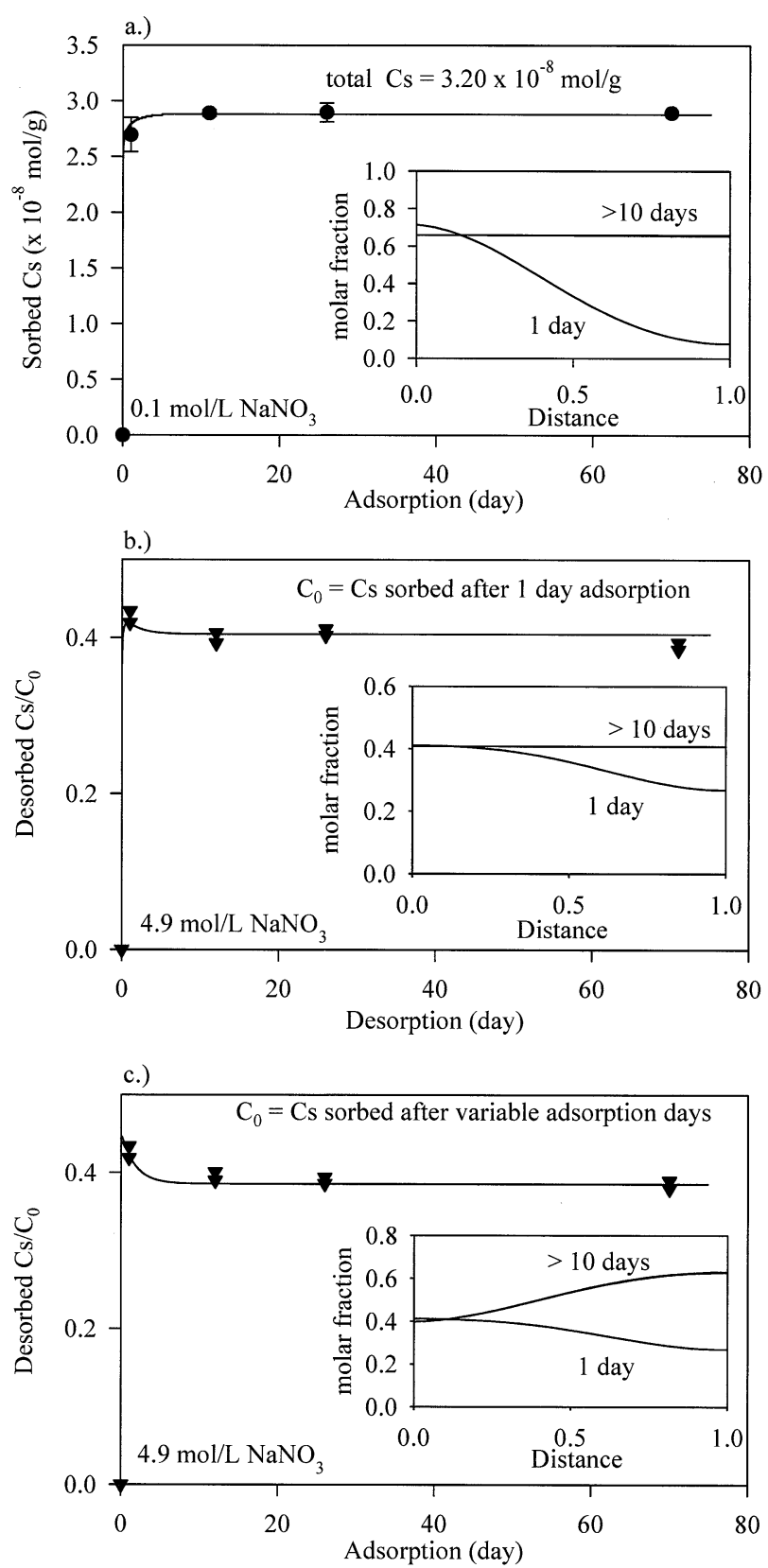

Fig. 11. Results of the coupled model of $\mathrm{Cs}^{+}$diffusion within edge-interlayer regions and equilibrium ion exchange on two external sites. (a) $\mathrm{Cs}^{+}$adsorption in $0.1 \mathrm{~mol} / \mathrm{L} \mathrm{NaNO}_{3}$ electrolyte (inset shows the intraparticle distributions as a function of time); (b) time-variant desorption in $4.9 \mathrm{~mol} / \mathrm{L} \mathrm{NaNO}_{3}$ after $1 \mathrm{~d}$ adsorption in $0.1 \mathrm{~mol} / \mathrm{L}$ $\mathrm{NaNO}_{3}$; (c) results after $1 \mathrm{~d}$ desorption in $4.9 \mathrm{~mol} / \mathrm{L} \mathrm{NaNO}_{3}$ after variable days of adsorption in $0.1 \mathrm{~mol} / \mathrm{L} \mathrm{NaNO}_{3}$.

interlayer/edge collapse in $\mathrm{K}^{+}$and $\mathrm{Rb}^{+}$electrolytes reduced i.) $\mathrm{Cs}^{+}$diffusivity within the intraparticle region, and ii.) the number of high affinity sites subject to equilibrium ion exchange.

Modeling $\mathrm{Cs}^{+}$desorption from the contaminated sediments was complicated by the long exposure time, the unknown intraparticle spatial distribution of radiocesium, the presence of secondary surface precipitates and other HLW-induced weath- ering effects (e.g., changes of site concentration and high/low affinity site distribution), and edge-interlayer diffusion and collapse in high $\mathrm{K}^{+} / \mathrm{Rb}^{+}$electrolyte system. Modeling desorption from the contaminated sediments (Fig. 13), required that the ratio of exchangeable $\mathrm{Cs}^{+}$(including equilibrium and kinetic) to the total sorbed $\mathrm{Cs}^{+}$on the sediment; and the fraction of high affinity sites also be considered as adjustable parameters. To provide consistency, the diffusion parameters and site density function were kept the same as for the "Above B" sediment in $\mathrm{K}^{+}$and $\mathrm{Rb}^{+}$electrolytes (Table 5). We also assumed that the ratio of external to intraparticle high affinity sites and the overall fraction of high affinity sites relative to the CEC were the same for all 4 contaminated samples (Table 5). The measured $\mathrm{Cs}^{+}$-CEC and total $\mathrm{Cs}^{+}$concentration for each contaminated sediment (Table 1) were used in the modeling.

The slab diffusion model produced reasonable simulations of the $\mathrm{Cs}^{+}$desorption results from the $\mathrm{SX}-108$ sediments (3A and 7A, Fig. 13) in both $\mathrm{KNO}_{3}$ and $\mathrm{RbNO}_{3}$ electrolytes using the parameters in Table 5. The 41-09-39 samples were not included here because of the large apparent variability in $\left[\mathrm{Cs}^{+}\right]_{\text {total }}$ between replicates (Figs. 3c,d). According to the model, desorption is described in two stages: i.) rapid ion exchange from external, high energy sites, and ii.) kinetic, diffusion-retarded ion exchange from internal, high affinity sites. Relative to the pristine sediment, an acceptable fit to the desorption data for the contaminated sediments was obtained by: i) increasing the high affinity site fraction $\left(E^{\text {in+ext }}\right.$ ) by $\sim 27 \%$, ii) increasing the ratio of external to internal high affinity sites $\left(E^{\text {ext }} / E^{\text {in }}\right.$; e.g., distributing the increased high affinity site concentration to particle exteriors rather than interiors), and iii) decreasing the fraction of sorbed $\mathrm{Cs}^{+}$that was exchangeable. The difference in the concentration and distribution of the high affinity sites relative to the pristine sediment was tentatively attributed to the effects of waste-sediment reaction. Unpublished results of the influence of waste-sediment reactions on the $\mathrm{Cs}^{+}$sorption to the Hanford site sediment qualitatively support this tenet (Ainsworth et al., personal communication). The nonexchangeable fraction (e.g., 63-55\%) was the sorbed $\mathrm{Cs}^{+}$pool that did not contribute to desorption over the time period of the experiment (e.g., $60 \mathrm{~d}$ ). This pool is effectively fixed by the solid phase.

A common set of parameters was found to describe the contaminated materials with the exception of the exchangeable fraction (Table 5). For obvious reasons, the exchangeable fraction was found to be a key variable, as it determined the total amount of $\mathrm{Cs}^{+}$that was desorbable from the solid. Equilibrium model calculations (not shown) indicated that the mass action pressure of both $2 \mathrm{~mol} / \mathrm{L} \mathrm{KNO}_{3}$ and $\mathrm{RbNO}_{3}$ was sufficient to displace all exchangeable $\mathrm{Cs}^{+}$from high affinity sites, if mass action equilibrium was achieved. Therefore, the total desorbed $\mathrm{Cs}^{+}$after $70 \mathrm{~d}$ was approximately equal to the exchangeable concentration, plus a small amount residual concentration bound to intraparticle high affinity sites that have not yet diffused to the aqueous phase. Consistent with the attainment of a common, final desorbed concentration for sample 7A in $\mathrm{KNO}_{3}$ and $\mathrm{RbNO}_{3}$ electrolytes (Fig. 13b), the computed exchangeable fraction in both electrolytes was approximately the same (e.g., 35\%). The smaller increase in $\mathrm{Cs}^{+}$desorption that was observed after the increase in concentration of $\mathrm{RbNO}_{3}$ from 0.5 to $2 \mathrm{~mol} / \mathrm{L}$ (compared to $\mathrm{KNO}_{3}$ ) was therefore interpreted as resulting from a global depletion in exchangeable $\mathrm{Cs}^{+}$ 
Table 5. Parameters used in diffusion modeling.

\begin{tabular}{|c|c|c|c|c|c|c|}
\hline \multirow[b]{2}{*}{ Electrolyte } & \multicolumn{6}{|c|}{ Uncontaminated sediment } \\
\hline & $\mathrm{D} / \mathrm{L}^{2}\left(\mathrm{day}^{-1}\right)$ & & $\mathrm{b}^{\mathrm{a}}$ & $E^{\text {ext }} / E^{\text {in b }}$ & & $E^{\text {in }+e x t}$ \\
\hline \multirow[t]{2}{*}{$\begin{array}{l}\mathrm{NaNO}_{3} \\
\mathrm{KNO}_{3} \\
\mathrm{RbNO}_{3} \\
\end{array}$} & $\begin{array}{l}9.0 \times 10^{-2} \\
2.5 \times 10^{-4} \\
2.5 \times 10^{-4} \\
\end{array}$ & & $\begin{array}{l}0.05 \\
0.05 \\
0.05 \\
\end{array}$ & $\begin{array}{l}0.61 \\
0.50 \\
0.42 \\
\end{array}$ & & $\begin{array}{l}4.5 \times 10^{-4} \\
4.5 \times 10^{-4} \\
4.5 \times 10^{-4}\end{array}$ \\
\hline & \multicolumn{4}{|c|}{${ }^{137} \mathrm{Cs}^{+}$-contaminated sediment } & \multicolumn{2}{|c|}{${ }^{137} \mathrm{Cs}^{+}(\mathrm{exe} / \mathrm{tot})^{\mathrm{c}}$} \\
\hline Sample & $\mathrm{D} / \mathrm{L}^{2}\left(\mathrm{day}^{-1}\right)$ & $b^{\mathrm{a}}$ & $E^{\text {ext }} / E^{\text {in b }}$ & $E^{\text {in }+e r}$ & $\mathrm{KNO}_{3}$ & $\mathrm{RbNO}_{3}$ \\
\hline $\begin{array}{l}\text { SX-108 3A } \\
\text { SX-108 7A } \\
41-09-397 \mathrm{~A} / \mathrm{B} / \mathrm{C} \\
41-09-399 \mathrm{~A} / \mathrm{B} / \mathrm{C}\end{array}$ & $\begin{array}{l}2.5 \times 10^{-4} \\
2.5 \times 10^{-4} \\
2.5 \times 10^{-4} \\
2.5 \times 10^{-4}\end{array}$ & $\begin{array}{l}0.05 \\
0.05 \\
0.05 \\
0.05\end{array}$ & $\begin{array}{l}0.84 \\
0.84 \\
0.84 \\
0.84\end{array}$ & $\begin{array}{l}5.7 \times 10^{-4} \\
5.7 \times 10^{-4} \\
5.7 \times 10^{-4} \\
5.7 \times 10^{-4}\end{array}$ & $\begin{array}{l}0.45 \\
0.37 \\
0.44 \\
0.45\end{array}$ & $\begin{array}{l}0.32 \\
0.34 \\
0.43 \\
0.42\end{array}$ \\
\hline
\end{tabular}

a $b$ is a parameter for the shape of intraparticle density function (see text).

${ }^{\mathrm{b}}$ Ratio of external vs. intraparticle high affinity sites.

${ }^{c}$ Ratio of exchangeable ${ }^{137} \mathrm{Cs}^{+}$(equilibrium + kinetic) to total ${ }^{137} \mathrm{Cs}^{+}$.

on high affinity sites. In contrast, the larger total desorbed $\mathrm{Cs}^{+}$ concentration for sample $3 \mathrm{~A}$ in $\mathrm{KNO}_{3}$ (Fig. 13) implied that the exchangeable fraction was significantly higher in $\mathrm{KNO}_{3}$ than in $\mathrm{RbNO}_{3}$ electrolyte (Table 5). This difference may result from interlayer collapse in $\mathrm{RbNO}_{3}$, or other unknown factors.

\section{CONCLUSIONS}

We have studied the desorption of $\mathrm{Cs}^{+}$from pristine/laboratory-spiked and contaminated subsurface sediment samples from the U.S. DOE Hanford site. Over 2 million $\mathrm{Ci}$ of ${ }^{137} \mathrm{Cs}^{+}$ has been released to vadose zone sediments at this site in the form of leaked high-level nuclear waste, and considerable concern exists with regard to the future migration of sorbed, in-ground residuals. Desorbability is a key factor governing future migration. The ${ }^{137} \mathrm{Cs}^{+}$-containing sediments studied here were contaminated over $30 \mathrm{yr}$ ago through accidental leakage of a caustic, hot brine containing approximately $10^{-4.5}$ $\mathrm{mol} / \mathrm{L}^{137} \mathrm{Cs}^{+}$

Sodium, $\mathrm{K}^{+}, \mathrm{Rb}^{+}$, and $\mathrm{NH}_{4}^{+}$electrolytes, and a selective
$\mathrm{Cs}^{+}$sorbent were used to desorb adsorbed $\mathrm{Cs}^{+}$through ion exchange mass action. Approximately $40 \%$ of the adsorbed pool was exchangeable (equilibrium plus kinetic). This percentage increased to $60-80 \%$ after long-term contact with acidified ammonium oxalate (AAO). AAO was thought to increase $\mathrm{Cs}^{+}$ desorption through the dissolution of microscopically thin, edge regions of phyllosilicates where high-affinity frayed edge sites are believed to reside. Four different contaminated sediment samples were studied that were collected at different (e.g., increasing) distances from the leaked, single shell waste tank. All the sediments exhibited common behavior.

Relative to the equilibrium state, $\mathrm{Na}^{+}$was the most effective desorbing cation. Desorption studies with $\mathrm{Cs}^{+}$-spiked pristine sediment equilibrated for short duration indicated that adsorbed $\mathrm{Cs}^{+}$, that was fully exchangeable in $\mathrm{Na}^{+}$electrolyte, became less exchangeable when placed in $\mathrm{K}^{+}$and $\mathrm{Rb}^{+}$electrolyte. This effect was attributed to the collapse of edge and partially expanded interlamellar regions resulting from saturation of the exchange complex with poorly hydrated $\mathrm{K}^{+}$and $\mathrm{Rb}^{+}$cations.
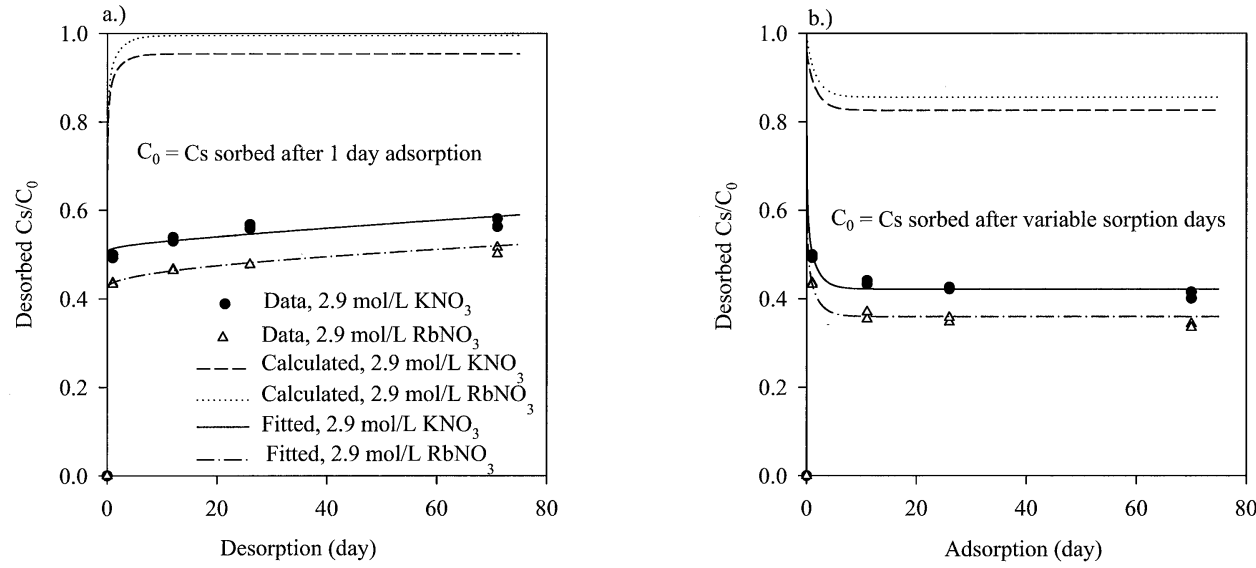

Fig. 12. Results of the coupled model of intraparticle diffusion with two-site external equilibrium ion exchange. Predicted and fitted desorption in $2.9 \mathrm{~mol} / \mathrm{L} \mathrm{KNO}_{3}$ and $\mathrm{RbNO}_{3}$ after $1 \mathrm{~d}$ adsorption (Fig. 12a), and $1 \mathrm{~d}$ of desorption after variable days of adsorption (Fig. 12b). 

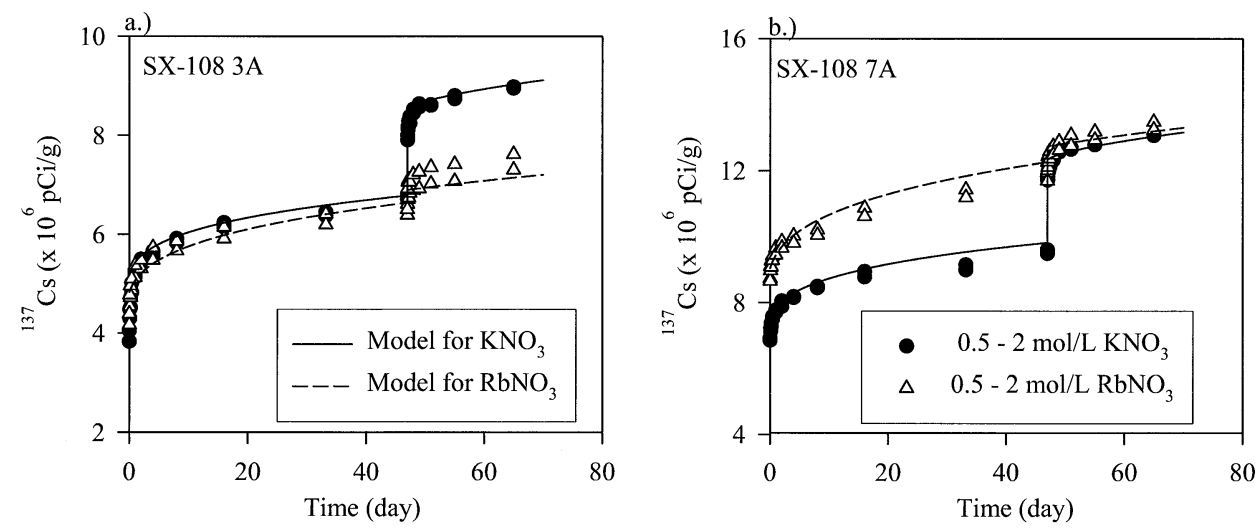

Fig. 13. Modeling results of the $\mathrm{Cs}^{+}$desorption from the $\mathrm{Cs}^{+}$-contaminated Hanford sediments using the coupled model of intraparticle diffusion with two-site external equilibrium ion exchange in $0.5-2 \mathrm{~mol} / \mathrm{L} \mathrm{KNO}_{3}$ and $\mathrm{RbNO}_{3}$ electrolytes.

Such collapse decreased the intraparticle diffusivity of adsorbed $\mathrm{Cs}^{+}$by many orders of magnitude. Desorption studies with the contaminated sediments in these same electrolytes showed evidence for collapse at higher electrolyte concentrations of $\mathrm{K}^{+}$and $\mathrm{Rb}^{+}$. Collapse lead to a significant decrease in the apparent exchangeable fraction.

$\mathrm{X}$-ray microprobe measurements of $\mathrm{Cs}^{+}$-sorbed mica from the pristine sediment showed $\mathrm{Cs}^{+}$in complex intraparticle distribution. Cesium was localized to select edge region, to the particle periphery, and also to internal channels running in parallel to the basal plane believed to be cleavage fractures. We assumed this distribution to be representative of micaceous mineral sorbents in the contaminated sediments, but were unable to verify by direct measurement. This particle distribution was amenable to description with a slab diffusion transport model that was linked to a two-site ion exchange model. The desorption resistant fraction that was not explicitly considered in this model, representing approximately $60 \%$ of the total adsorbed pool, has likely diffused into $1.0 \mathrm{~nm}$ phyllosilicate regions with dominant $\mathrm{K}^{+}$saturation.

Our results have shown that a minimum of $24 \%$ of the adsorbed $\mathrm{Cs}^{+}$pool in the contaminated sediment is responsive to ion exchange mass action with aqueous electrolyte cations. The exchangeable fraction varies up to $56.4 \%$ depending on the nature of the electrolyte cation and its concentration. Accurate in-situ calculations of desorption in these particular sediments requires explicit consideration of $\mathrm{K}^{+}$concentrations in the aqueous and exchanger phase because of its potential to collapse edge and interlamellar regions with attendant effects on ${ }^{137} \mathrm{Cs}^{+}$exchangeability and intraparticle diffusivity.

Acknowledgments-This research was supported by the U.S. Department of Energy (DOE) through the Environmental Management Sciences Program (EMSP) and the Hanford Science and Technology Program managed by the Groundwater Protection Project. Pacific Northwest National Laboratory (PNNL) is operated for the DOE by Battelle Memorial Institute under contract DE-AC06-76RLO 1830. We thank Dr. Y. Lin at PNNL for providing SAMMS materials. We also thank two reviewers for their valuable comments and suggestions.

Associate editor: J. D. Rimstidt

\section{REFERENCES}

Ball W. P. and Roberts P. V. (1991) Diffusive rate limitations in the sorption of organic chemicals. In Organic Substances and Sediments in Water: Processes and Analytical, Vol. 2 (ed. R. A. Baker), pp. 273-310. Lewis Publishers.

Barrer R. M. and Klinowski J. (1974) Ion-exchange selectivity and electrolyte concentration. J. Chem. Soc. Farad. Trans. I 70, 20802091.

Brouwer E., Baeyens B., Maes A., and Cremers A. (1983) Cesium and rubidium ion equilibria in illite clay. J. Phys. Chem. 87, 1213-1219.

Comans R. N. J., Haller M., and De Preter P. (1991) Sorption of cesium on illite: Non-equilibrium behavior and reversibility. Geochim. Cosmochim. Acta. 55, 433-440.

Comans R. N. J. and Hockley D. E. (1992) Kinetics of cesium sorption on illite. Geochim. Cosmochim. Acta 56, 1157-1164.

Cornell R. M. (1993) Adsorption of cesium on minerals: A review. $J$. Radioanal. Nucl. Chem. Articles 171, 483-500.

Cowan C. E., Zachara J. M., and Resch C. T. (1991) Cadmium adsorption on iron oxides in the presence of alkaline-earth minerals. Environ. Sci. Technol. 25, 437-446.

Cremers A., Elsen A., De Preter P., and Maes A. (1988) Quantitative analysis of radiocesium retention in soils. Lett. Nat. 335, 247-249.

Cussler E. L. (1995) Diffusion: Mass Transfer in Fluid Systems. Cambridge University Press.

De Preter P. (1990) Radiocesium retention in the aquatic, terrestrial and urban environment: A quantitative and unifying analysis. Katholieke Unversiteit. Ph.D dissertation.

Di Toro D. M., Mahoney J. D., Kirchgraber P. R., O'Byrne A. L., Pasquale L. R., and Piccirilli D. C. (1986) Effects of nonreversibility, particle concentration and ionic strength on heavy metal sorption. Environ. Sci. Technol. 20, 55-61.

Do D. D. (1998) Adsorption Analysis: Equilibrium and Kinetics. Imperial College Press.

Eberl D. D. (1980) Alkali cation selectivity and fixation by clay minerals. Clays Clay Miner. 28, 161-172.

Evans D. W., Alberts J. J., and Clark R. A. (1983) Reversible ionexchange fixation of cesium-137 leading to mobilization from reservoir sediments. Geochim. Cosmochim. Acta 47, 1041-1049.

Evans J. C., Dresel P. E., Farmer O. T., Conrad M. S., and DePaolo D. J. (2001) Transport mechanisms inferred by isotope geochemistry. In Digest of $S \& T$ Program Evaluations, S-SX FIR Appendix D, pp. D227-D240. Pacific Northwest National Laboratory.

Felmy A. R. (1995) GMIN, A computerized chemical equilibrium program using a constrained minimization of the Gibbs free energy: Summary report. In Chemical Equilibrium and Reaction Models (eds. R. H. Loeppert, A. P. Schwab, and S. Goldberg) pp. 377-407. Soil Science Society of America.

Kim Y., Cygan R. T., and Kirkpatrick R. J. (1996) ${ }^{133}$ Cs NMR and XPS investigation of cesium adsorbed on clay minerals and related phases. Geochim. Cosmochim. Acta 60, 1041-1052.

Le Roux J., Rich C. I., and Ribbe P. H. (1970) Ion selectivity by weathered mica as determined by electron microprobe analysis. Clays Clay Miner. 18, 333-338. 
Lin Y., Fryxell G. E., Wu H., and Engelhard M. (2001) Selective sorption of cesium using self-assembled monolayers on mesoporous supports. Environ. Sci. Technol. 35, 3962-3966.

Liu D.-C., Hsu C. N., and Chung C. L. (1994) Ion-exchange and sorption kinetics of cesium and strontium in soils. Appl. Radiat. Isotopes 46, 839-846.

Liu C., Zachara J. M., and Smith S. C. (2003) A cation exchange model to describe Cs sorption at high ionic strength in subsurface sediments at Hanford site, USA. J. Contam. Hydrol.,in press.

Loeppert R. L. and Inskeep W. P. (1996) Iron. In Methods of Soil Analysis, Part 3-Chemical Methods, Vol. 5 (eds. D. L. Sparks et al.), pp. 639-664. Soil Science Society of America.

McKinley J. P., Zeissler C. J., Zachara J. M., Serne R. J., Lindstrom R. M., Schaef H. T., and Orr R. D. (2001) Distribution and retention of ${ }^{137} \mathrm{Cs}$ in sediments at the Hanford site, Washington. Environ. Sci. Technol. 35, 3433-3441.

Pitzer K. S. (1994) Ion Interaction Approach: Theory and Data Correlation. CRC Press.

Poinssot C., Baeyens B., and Bradbury M. H. (1999) Experimental and modeling studies of cesium sorption on illite. Geochim. Cosmochim. Acta 63, 3217-3227.

Sawhney B. L. (1967) Interstratification in vermiculite. Clays Clay Miner. 15, 75-84.

Sawhney B. L. (1969) Regularity of interstratification as affected by charge density in layer silicates. Soil Sci. Soc. Am. Proc. 33, 42-46.

Sawhney B. L. (1972) Selective sorption and fixation of cations by clay minerals: A review. Clays Clay Miner. 20, 93-100.

Serne R. J., Last G. V., Gee G. W., Schaef H. T., Lanigan D. C., Lindenmeier C. W., Clayton R. E., LeGore V. L., Orr R. D., O'Hara M. J., Brown C. F., Burke D. B., Owen A. T., Kutnyakov I. V., and Wilson T. C. (2001a) Geologic and Geochemical Data Collected from Vadose Zone Sediments from Borehole SX 41-09-39 in the S/SX Waste Management Area and Preliminary Interpretations.Pacific Northwest National Laboratory.

Serne R. J., Schaef H. T., Last G. V., Lanigan D. C., Lindenmeier C. W., Clayton R. E., LeGore V. L., O'Hara M. J., Brown C. F., Orr R. D., Kutnyakov I. V., Wilson T. C., Burke D. B., Williams B. A., and Bjornstad B. N. (2001b) Geologic and Geochemical Data Collected from Vadose Zone: Sediments from the Slant Borehole under SX-108 in the S/SX Waste Management Area and Preliminary Interpretations.Pacific Northwest National Laboratory.

Smith J. T. and Comans R. N. J. (1996) Modeling the diffusive transport and remobilization of ${ }^{137} \mathrm{Cs}$ in sediments: The effects of sorption kinetics and reversibility. Geochim. Cosmochim. Acta. 60, 995-1004.

Sposito G. (1994) Chemical Equilibria and Kinetics in Soils. Oxford Clarendon Press.

Steefel C., Carroll S., Zhao P., and Roberts S. (2002) Reactive transport experiments investigating the migration of ${ }^{137} \mathrm{Cs}$ in sediments beneath the Hanford SX tank farm. J. Contam. Hydrol., in press.

Weiss C. A., Kirkpatrick R. J., and Altaner S. P. (1990a) The structural environments of cations adsorbed onto clays: ${ }^{133} \mathrm{Cs}$ variable-temperature MASA NMR spectroscopic study of hectorite. Geochim. Cosmochim. Acta 54, 1655-1669.

Weiss C. A., Kirkpatrick R. J., and Altaner S. P. (1990b) Variations in interlayer cation sites of clay minerals as studied by ${ }^{133} \mathrm{Cs}$ MAS nuclear magnetic resonance spectroscopy. Am. Mineral. 75, 970982.

Zachara J. M., Smith S. C., Liu C., McKinley J. P., Serne R. J., and Gassman P. L. (2002) Sorption of $\mathrm{Cs}^{+}$to micaceous subsurface sediments from the Hanford site, USA. Geochim. Cosmochim. Acta 66, 193-211. 